OPEN ACCESS

Edited by:

Christiane Pienna Soares,

Sao Paulo State University, Brazil

Reviewed by:

Carlos Moya,

Université libre de Bruxelles, Belgium

Hans Georg Breunig,

Saarland University, Germany

Sebastian Patrick Schwaminger,

Massachusetts Institute of

Technology, United States

${ }^{*}$ Correspondence:

Koiti Araki

koiaraki@iq.usp.br

Specialty section:

This article was submitted to

Biomedical Nanotechnology,

a section of the journal

Frontiers in Nanotechnology

Received: 02 July 2021

Accepted: 25 August 2021

Published: 21 September 2021

Citation:

Kawassaki RK, Romano M, Dietrich N and Araki K (2021) Titanium and Iron

Oxide Nanoparticles for Cancer

Therapy: Surface Chemistry and

Biological Implications.

Front. Nanotechnol. 3:735434.

doi: 10.3389/fnano.2021.735434

\section{Titanium and Iron Oxide Nanoparticles for Cancer Therapy: Surface Chemistry and Biological Implications}

\author{
Rodrigo Ken Kawassaki, Mariana Romano, Natasha Dietrich and Koiti Araki * \\ Laboratory of Supramolecular Chemistry and Nanotechnology, Department of Fundamental Chemistry, Institute of Chemistry,
} University of São Paulo, São Paulo, Brazil

Currently, cancer is among the most challenging diseases due to its ability to continuously evolve into a more complex muldimentional system, in addition to its high capability to spread to other organs and tissues. In this context, the relevance of nanobiomaterials (NBMs) for the development of new more effective and less harmful treatments is increasing. NBMs provide the possibility of combining several functionalities on a single system, expectedly in a synergic way, to better perform the treatment and cure. However, the control of properties such as colloidal stability, circulation time, pharmacokinetics, and biodistribution, assuring the concentration in specific target tissues and organs, while keeping all desired properties, tends to be dependent on subtle changes in surface chemistry. Hence, the behavior of such materials in different media/environments is of uttermost relevance and concern since it can compromise their efficiency and safety on application. Given the bright perspectives, many efforts have been focused on the development of nanomaterials fulfilling the requirements for real application. These include robust and reproducible preparation methods to avoid aggregation while preserving the interaction properties. The possible impact of nanomaterials in different forms of diagnosis and therapy has been demonstrated in the past few years, given the perspectives on how revolutionary they can be in medicine and health. Considering the high biocompatibility and suitability, this review is focused on titanium dioxide- and iron oxide-based nanoagents highlighting the current trends and main advancements in the research for cancer therapies. The effects of phenomena, such as aggregation and agglomeration, the formation of the corona layer, and how they can compromise relevant properties of nanomaterials and their potential applicability, are also addressed. In short, this review summarizes the current understanding and perspectives on such smart nanobiomaterials for diagnostics, treatment, and theranostics of diseases.

Keywords: smart nanobiomaterials, cancer theranostics, titanium dioxide nanoparticles (TiO2 NP), iron oxide nanoparticles (IO NP), nanomedicine, corona effect, nanoparticle surface chemistry, nanoparticle stabilizing agents 


\section{INTRODUCTION}

Cancer is a disease with a great impact on the world population. According to the most recent World Health Organization's (WHO) report, among noncommunicable diseases, cancer was the leading cause of death in global population in 2019 (WHO, 2020). Cancer is commonly caused by accumulation of genetic mutations, which yield cells with high genomic instability and high capability of replication that finally leads to tissue invasion and tumor formation (Hanahan and Weinberg, 2011). Furthermore, the characteristics of cancer cells change and evolve with the growth of the solid tumor, generating a quite complex ecosystem, where the diagnosis and prescription of the treatment are quite challenging tasks.

Cancer treatment protocols such as surgery, radiotherapy, and chemotherapy are already consolidated. However, these are not always the most suitable ones for the patient clinical conditions since each cancer subtype has many characteristics that are specific to the organ of origin, thus increasing, even more, the complexity of diagnostics and treatment. Furthermore, such conventional therapies do not achieve high efficiency in all cases as they can promote unwanted selection of the most resistant and eventually aggressive subtypes. This can lead to an apparent improvement of patients' clinical conditions, but that can degenerate rapidly due to recurrence with increased resistance to antitumor drugs (Cree and Charlton, 2017). Another negative feature of the current therapies is the frequent emergence of undesirable side effects, directly impacting the quality of life of the patients. In this context, nanotechnology shows special relevance, as it enables the optimization of the materials properties for the desired application. Hence, more effective and less harmful treatments of diseases are expected using nanomaterials since they make possible the combination of several functionalities on a single system in a synergic way (Svenson, 2013).

Nanotechnology aims at the development of materials with at least one of its dimensions in the nanometric scale (1 to $\sim 100 \mathrm{~nm})$ that can present unique physico-chemical properties as a consequence of their nanometric dimensions and associated high surface areas (Boverhof et al., 2015). Nanomaterials properties can be modified and controlled according to their composition, shape, size, and surface chemistry, fundamental to make them suitable for applications in catalysis, energy conversion systems, sensors, medical diagnostics, and treatment, among others (Teja and Koh, 2009). Among them, possibly those for biomedical application are the most rewarding but also the most challenging ones, given the stringent requirements of purity, biocompatibility, stability, and effectiveness. Accordingly, they require the most exquisite functionalization processes to incorporate all the needed characteristics to make them suitable for real applications. For instance, the biological properties can be modulated by conjugating on their surface: therapeutic and bioactive molecules, vectorizing agents (antibodies, antigens, aptamers, and peptides), and molecular species for diagnostics such as fluorescent biomarkers, contrast agents, and radiotracers (Stark, 2011; McNamara and Tofail, 2017). Their combination in a single platform, i.e., on each single nanoparticle, can generate smart functional nanobiomaterials (NBMs) whose representative scheme is illustrated in Figure 1. NBMs focused on complex diseases such as cancer are emerging with the evolution especially of multi-conjugation methods providing a good control on the surface chemistry as well as on the colloidal stability.

Currently, increasing efforts are being focused on the development of NBMs aiming at the simultaneous diagnosis and treatment of cancer, an approach called theranostics (Jang et al., 2016; Dadfar et al., 2019). Promising materials have been achieved, but only a few were translated to clinical trials and approved by regulatory agencies. The heterogeneity and complexity of cancer as well as the lack of a more thorough understanding about the interactions of nanomaterials with biological systems are imposing difficulties (Singh et al., 2020). Hence, studies addressing issues such as nanomaterials fate in biological systems, the mechanisms of nanobio interaction, and further understanding of pathological, inflammatory, and other biological responses are fundamental. Moreover, to fully address these aspects, a multidisciplinary team encompassing different areas of knowledge such as chemistry, physics, biology, pharmacy, and medicine is necessary. The contribution of specialists with different expertise should lead to faster and more accurate analyses and solutions of the several issues. In this context, we expect to contribute to the progress of the field from a chemical perspective.

Therefore, this review is aimed to present the state of the art on NBMs based on titanium dioxide $\left(\mathrm{TiO}_{2}\right)$ and iron oxide (IO), discussing the current context and perspectives on nanomaterials for cancer diagnostics and/or treatment. Also, the correlation of surface chemistry with the mechanisms of cell-NBM interaction is addressed, as well as the effects induced by common phenomena such as aggregation and agglomeration, and corona effect, and how they can compromise the nanomaterials properties and change their biological fate. These will be illustrated and discussed based on the most recent literature, thus providing new perspectives and clues on how addressing the challenges for the development of new nanoagents for cancer diagnostics, therapy, and theranostics.

\section{SURFACE CHEMISTRY, TARGETING, AND FATE OF NANOPARTICLES}

The control on nanomaterials' surface chemistry is fundamental when designing NBMs for medical and biomedical applications since the molecular layer acts as the interface with the surrounding environment, thus playing a major role in the interactions and determining the biological fate of nanomaterials (Nel et al., 2009). Furthermore, the conjugation of different molecules on the surface enables the modulation of their physico-chemical properties and the incorporation of various functionalities, to adjust their biological activity.

\section{Biological Impacts of the Coating Layer: Colloidal Stability and Stealthing}

Colloidal stability (CS) is a critical property of nanosystems for biomedical applications that relies on the interactions of the 


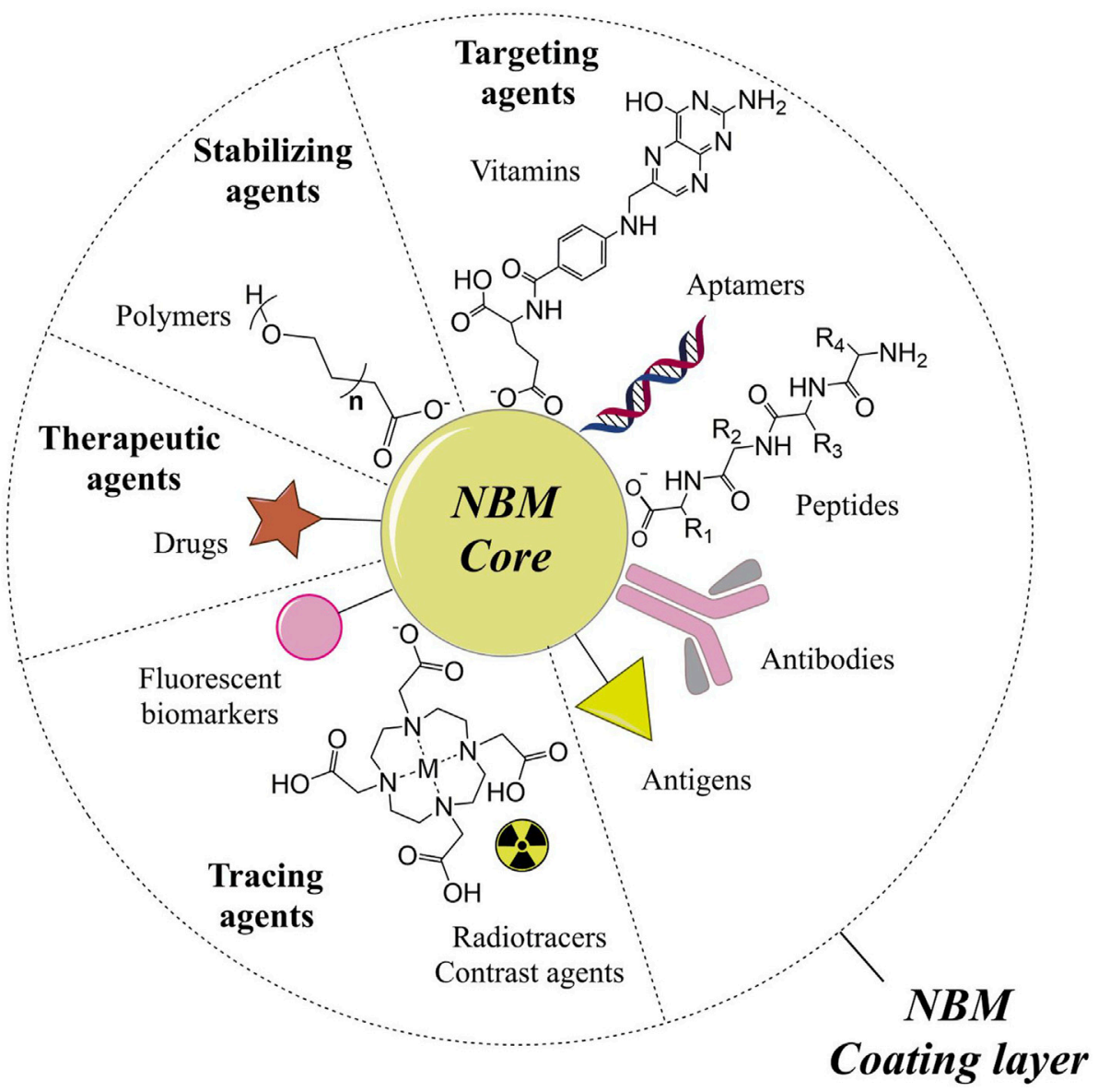

FIGURE 1 | Scheme illustrating the possible components of multifunctional nanobiomaterials (NBMs). The NBM core can be made of materials such as metals, metal oxides, polymers, lipids, among others, but this review is focused on NBMs based on $\mathrm{NBMs}$ with $\mathrm{IO}$ and $\mathrm{TiO}_{2}$ cores conjugated to different molecules (coating layer or shell). These molecules are classified according to the functionality they add up to the NBM: therapeutic agents (e.g. drugs); stabilizing agents (e.g. polymers); targeting agents such as vitamins, aptamers, peptides, antibodies, and antigens; and tracing agents such as fluorescent biomarkers, radiotracers, and contrast agents. The diameter of the core and the thickness of the molecular coating layer are not been shown in the actual proportion in the scheme, as they may vary according to each engineered NBM.

continuous liquid phase and the dispersed phase. Specifically, it is achieved when nanoparticles are prevented from aggregate/ agglomerate, remaining dispersed in the medium. Two are the main factors contributing to CS: the NPs intrinsic interaction with the solvent and the attractive or repulsive NP-NP interactions. Since the biological media are usually aqueous, highly dispersible NPs are achieved when hydrophilic molecules are bound on their surface. Furthermore, conjugation of stabilizing agents reduces the probability of direct interaction between NPs core, which presents an enhanced area/volume ratio and high surface energy, which could lead to undesirable aggregation processes. Accordingly, different molecules have been tested to get stable NPs dispersions in biological environments, exploring the steric and electrostatic effects (Mo et al., 2016).

Steric stabilization usually is achieved by the conjugation of high molecular weight polymers on the NPs surface. The presence of such coating layer increases the repulsive forces between NPs due to two main factors: 1) the large volume of the polymeric chains prevents the NPs core to come into close contact while decreasing the attractive forces, thus leading to an excluded volume effect, and 2) when two NPs approach each other, a region with a high density of polymers and a diminished number of solvent molecules is created between them, leading to a repulsive osmotic pressure effect (Elbasuney, 2017). Hence, the combination of these two and the repulsive effect caused by the motion of dangling side chains provide what is called the steric stabilization effect. Synthetic polymers such as polyethylene glycol (PEG) and polyacrylic acid (PAA), as well as natural polymers such as bovine serum albumin (BSA), chitosan, and dextran, are among the most explored stabilizing agents in the biomedical area (Arteaga-Cardona et al., 2016; Tegafaw et al., 2017; Abdollah et al., 2018; Nosrati et al., 2018; Dhavale et al., 2021). Particularly, PEG has been extensively studied since prolongs the blood circulation time of its conjugates (e.g. drugs, proteins, NPs) by preventing the adsorption of opsonins, specific biomolecules that activate the immune system. Also, the so-called "stealth effect" inhibits a quick 
blood clearance, allowing the NBMs accumulation in their target sites, a fundamental feature in cancer theranostics. However, concerns have been raised about PEG effectiveness in clinical trials considering the possible production of anti-PEG antibodies (aPAb) upon exposure (Grenier et al., 2018). In fact, some studies detected pre-existing $\mathrm{aPAb}$ even in individuals that have never been exposed to PEG-containing treatments (Yang and Lai, 2015; Yang et al., 2016). This was assigned to the growing medicinal and consumer use of PEG, including in hygiene and cosmetic products and food additives, leading to involuntary exposure of population and consequent activation of that immune response. Such hypothesis was tested by Grenier et al. who injected NPs of poly(ethyleneglycol)-b-poly(lactic-co-glycolic acid) copolymer in mice 7 days after exposing them to different materials conjugated with PEG. Interestingly, the PEGylated nanomaterials were more rapidly cleared by the experimental groups in comparison with the control group that was injected only with PBS solution. However, PEGylated BSA and the free polymer did not change the clearance parameters maintaining the same rates as the control. Such difference was assigned to the conformation of the PEG chains on NBMs surface, which might facilitate their binding to aPAbs (Grenier et al., 2018). On the other hand, Joh et al. investigated the antigenicity of the 3D-hyperbranched derivative of PEGdenominated poly(oligo(ethyleneglycol)methylether methacrylates) (POEGMA), which has ethylene glycol (EG) oligomers as side chains on a poly(methylmethacrylate) backbone, in a "bottlebrush" architecture. POEGMAs with a variable number of EG repeat units were grown on solid surfaces and challenged against the plasma of aPAb-positive patients. Interestingly, the structures containing branches with 2 or 3 EG repeats presented a reduced recognition by anti-PEG antibodies, probably due to steric factors inhibiting their binding to the EGs (Joh et al., 2019). That result was supported by a previous work showing that a therapeutic peptide conjugated to POEGMA has an enhanced circulation time and reduced antigenicity by aPAb in mice (Qi et al., 2017). Considering the above discussion and that this approach is extensively used in NBMs for cancer theranostics, further studies are needed to fully understand the PEG recognition mechanism by anti-PEG antibodies in the surface and evaluate whether other polymers can induce acquired immunogenicity as well.

Another classical approach for colloidal stabilization is by modulation of the electrostatic interactions between the NPs (Mo et al., 2016) that can be achieved by the conjugation of electrically charged molecules on the NPs surfaces thus conferring high enough zeta potentials to them. Hence, when two NPs with the same charge come into close range, the Coulombic electrostatic repulsion forces will eventually overcome the attraction forces, inhibiting their aggregation, and thus imparting colloidal stability to the system. However, this approach is highly dependent on factors such as the $\mathrm{pH}$ and the ionic strength of the medium. For instance, the cellular culture mediums (CCMs) generally present a high concentration of inorganic salts as well as different types of biomolecules. The high ionic strength tends to compress the double electric layer of NPs, decreasing its thickness (Moore et al.,
2015) and shortening the range of action of the electrostatic repulsive forces, thus favoring the approach and agglomeration of NPs. Moreover, the adsorption of biomolecules present in the CCM, or ligand exchange processes, may change the NPs zeta potential thus inducing their aggregation. In fact, the binding energy of molecular species on NP's surface is strongly dependent on the coordination strength of the anchoring groups.

Generally, a zeta potential equal to or larger than about $30 \mathrm{mV}$ is considered enough to assure CS in an aqueous solution (Clogston and Patri, 2011). However, this can be misleading when the measurement is carried out in pure water, and not in a complex media such as CCMs which simulate better an biological environment containing different salts including calcium salts (Moore et al., 2015). In this case, negatively charged nanomaterials stabilized by carboxylate, phosphate, and phosphonate groups can be easily precipitated out since $\mathrm{Ca}^{2+}$ ions can act as bridging group generating coordination polymer-like materials (Safi et al., 2011). Also, an increase in ionic strength tends to compact the electric double layer and decreases the electrostatic repulsion granted by charged particles (Edwards and Williams, 2004). Accordingly, only ligands containing very weakly coordinating negatively charged group (e.g. sulfonate in tiron ligand) can be effective for electrostatic stabilization in a wide range of $\mathrm{pHs}$, thus conferring good CS in biological media. However, there is no other way to overcome the destabilizing effect of ionic strength unless by exploiting steric forces, especially those provided by the motion of dangling side chains and substituents (Mo et al., 2016).

In this context, it is also very important controlling the size, electric charge, and morphology since larger particles are easily recognized by the mononuclear phagocytic system (MPS) and cleared by phagocytosis or endocytosis (e.g. in liver), whereas very small particles $(<5-10 \mathrm{~nm})$ tend to be renal cleared (Tsoi et al., 2016; Ferretti et al., 2021). Preferentially, the core and the conjugated molecular layer should be biocompatible since some materials may elicit toxic effects related to the core (e.g. $\mathrm{CdS}$ ) exposition, which have been associated with oxidative stress (Soenen et al., 2015), but can be turned biocompatible when protected by an inert shell (e.g. silica) (Veeranarayanan et al., 2012).

\section{Nanoparticles Aggregation and Biological Activity}

In the context of nanoparticles, several tests must be performed to investigate the suitability of metal oxide NPs for biomedical applications, where the cytotoxicity and in vivo toxicity assays play a fundamental role. The initial studies usually are carried out by in vitro assays, where the relevance of two recurrent phenomena are being overlooked or undersestimated: aggregation and agglomeration. Both terms are associated with the phenomenon of NPs sticking together leading to the formation of larger structures, but they hide a very important conceptual difference. Nevertheless, a similar meaning tends to be attributed in the literature such that both are employed to describe the dispersion state of nanoparticles in a medium. Accordingly, before discussing the implications of the agglomeration and aggregation processes, it is interesting to 


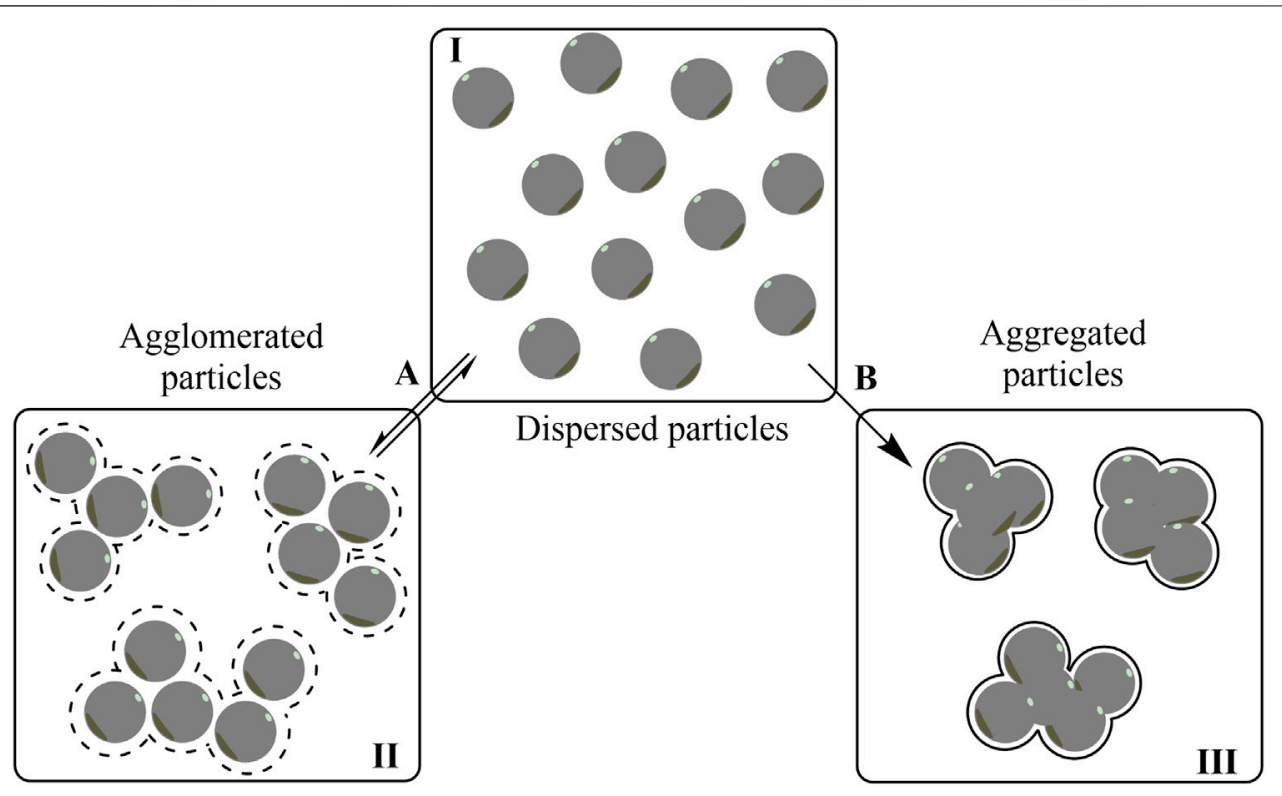

FIGURE 2 | Scheme illustrating the difference between agglomerated (II) and aggregated (III) particles. In the agglomeration process (A), the initially dispersed particles (I) interact with each other in a reversible way by weak forces, whereas they are held tightly together by strong forces, in an irreversible way, upon aggregation (B).

address the meaning of these two terms and how they influence the properties of nanomaterials dispersions.

According to the definitions of the International Organization for Standardization, 2015 (ISO), agglomerate is defined as "a collection of weakly or medium strongly bound particles where the resulting external surface area tends to approach the sum of the surface areas of the individual components. The forces holding an agglomerate together are weak forces, for example, van der Waals forces, or simple physical entanglement." This contrasts with the definition of aggregate that is "a particle comprising strongly bonded or fused particles where the resulting external surface area is significantly smaller than the sum of calculated surface areas of the individual components. The forces holding an aggregate together are strong forces, for example, covalent or ionic bonds, or those resulting from sintering or complex physical entanglements, or otherwise combined former primary particles" (ISO, 2015). Accordingly, the agglomeration process is reversible, whereas the aggregation process is irreversible (Alemán et al., 2007) since nanoparticles cores are closely and strongly bound together, as illustrated schematically in Figure 2.

From a thermodynamic point of view, agglomerates can be described as a set of nanoparticles with low surface energy that are weakly interacting with each other through the protecting/ functionalization molecular layer. Thus, a simple dilution or a change of solvent can shift the equilibrium in a reversible way destroying the agglomerates, similarly to a conventional precipitation process that can be reversed by shifting the solubility equilibrium. The formation and stability of these clustered systems can be explained by the Derjaguin-LandauVerwey-Overbeek (DLVO) theory (Hoek and Agarwal, 2006; Alemán et al., 2007), considering the forces acting on each NP in the agglomerates, and the interparticle interactions, such as the van der Waals and electrostatic forces, to explain the CS. The DLVO theory is based on the net potential energy of the particles system, more specifically the resultant of the attractive and repulsive forces between the NPs, to predict the conditions under which the system will be stable or unstable in relation to the agglomerates/aggregates. Additional steric forces are included in the DLVO theory, mainly when the nanoparticles' surfaces are covered with high molecular weight molecules such as polymers (Hoek and Agarwal, 2006; Striolo and Egorov, 2007). Although this theoretical approach is satisfactory in predicting the CS of NPs, they offer little or no information on the size distribution of the agglomerates and aggregates. Accordingly, other approaches are needed to predict their actual sizes, such as by potential of mean force (PMF) calculations or by experimental evaluation by light scattering techniques such as dynamic light scattering (DLS) and nanoparticle tracking analysis (NTA). Electron microscopy techniques such as scanning electron microscopy (SEM) and transmission electron microscopy (TEM) can also be used for that purpose (Striolo and Egorov, 2007). The scattering techniques offer the advantage of analyzing the particles directly in the dispersions, whereas the sample preparation needed for SEM and TEM can completely change the size of the agglomerates/aggregates but can provide a better perspective on the core size of individual NPs.

The phenomenon of nanoparticles aggregation should be considered when the protecting molecular layer is not tight and/or strong enough to avoid the direct contact of the core material with high surface energy, leading to the formation of strong bonds holding them together in an irreversible way (Hotze et al., 2010). The physical dimensions of such larger structures can affect critical parameters such as the reactivity, surface area, 
bioavailability, and toxicity. The aggregated structures must therefore be carefully evaluated and considered when interpreting the transport, biodistribution, and toxicity data of nanomaterials.

In vitro tests have been required to evaluate the risk and toxicologic properties since a much larger scale production of nanoparticles with several different surface functionalizations has being started (Stone et al., 2009; Cho et al., 2013). Even though in vitro assays are simple to carry out than in vivo experiments, there are some key differences that must be considered in the case of nanomaterials. Cells are cultured in a medium that provides the essential nutrients for cellular growth and proliferation in controlled osmolarity and $\mathrm{pH}$ conditions. Hence, the medium contains several inorganic salts and biomolecules which can change the colloidal stability of nanoparticles, as described by Moore et al. that have provided a systematic picture of the composition of the commonly used CCM (Moore et al., 2015).

Safi et al. proposed an elegant series of tests to verify the CS of IO NPs in biological media. Briefly, they dispersed the NPs in PBS, fetal bovine serum (FBS) supplemented and nonsupplemented Roswell Park Memorial Institute (RPMI) CCM, water containing divalent metal cations such as $\mathrm{Ca}^{2+}$ and $\mathrm{Mg}^{2+}$, and FBS supplemented medium which was previously incubated with the cells that were used in the experiments (Safi et al., 2011). We would like to call your attention to this last condition since cells do release intracellular components into the CCM that may interfere in nanoparticles CS. Therefore, this simple set of experiments can provide critical information whether NPs will agglomerate/aggregate or not in the medium as a consequence of the cellular activity. In fact, such an initial assessment is strongly recommended and must be carried out to improve the confidence in their dispersion properties in the biological medium before proceeding. Unfortunately, most published studies provide the CS to validate the assays only considering the size distribution and $\zeta$-potential measured in water, typically by DLS technique. However, as emphasized by Moore et al., water is a completely different environment as compared with physiological media. In fact, CCMs also have compositions that contrast with animal and human blood/serum as well (Moore et al., 2015). Hence, CS needs to be meticulously evaluated; otherwise, it can be the source of misinterpretations and eventual unintentional misleading data. For instance, Safi et al. further demonstrated that citrate-coated (CA) IO NPs did aggregate, while PAA-coated ones remained dispersed in RPMI medium. They also showed that the agglomerated/aggregated CA-NPs did adsorb on 2139 human lymphoblastoid cell membranes and are more rapidly internalized than the PAA-NPs (Safi et al., 2011). Mondini et al. compared the behavior of IO NPs conjugated with zwitterionic dopamine sulfonate (ZDS) and 2-(2methoxyethoxy)ethoxy acid (MEEA). The incubation with HepG2 hepatocarcinoma cell lines demonstrated that the MEEA-NPs form aggregates and were internalized more effectively than the ZDS-coated ones, which remained fully dispersed (Mondini et al., 2015). As illustrated by the above examples, agglomeration/aggregation changes the interaction of NPs with biological systems. In fact, Wills et al. pointed out that the bioavailability and thus the toxicological dose-response data of aggregates are different enough from the corresponding dispersed NPs such that these cannot be considered representative of the sample in real applications (Wills et al., 2017).

Generally, NPs aggregation takes place in an uncontrolled manner generating aggregated particles with a broad distribution of sizes and shapes, thus changing the cellular uptake mechanism due to the size limitation of the endosomes involved in the internalization process. For instance, caveolae-dependent endocytosis leads to the formation of vesicles with about $100 \mathrm{~nm}$ diameter, while phagosomes can be as large as $10 \mu \mathrm{m}$ (Donahue et al., 2019; Almeida et al., 2021). Accordingly, the uptake efficiency of non-spherical NPs should be significantly influenced by the direction of approach with cells. In fact, it was demonstrated by Albanese et al. and Champion et al. that the uptake of NPs and their aggregates are dependent on the contact angle with the cell membrane (Champion and Mitragotri, 2006; Albanese and Chan, 2011). Accordingly, special attention should be addressed to differentiate adsorbed NPs from those effectively internalized by cells (Alkilany et al., 2016) since most quantification methods are not able to distinguish them.

Finally, the aggregated particles can interfere with the therapeutic effectiveness of NPs. For instance, Guibert et al. demonstrated that the aggregation state influences the efficiency of magnetic hyperthermia of magnetic IO NPs. They found out that loosely bond small agglomerates do not cause major changes in the specific loss power, but large dense aggregates decreased significantly the hyperthermia efficiency (Guibert et al., 2015).

\section{Corona Effect}

One of the main routes for administration of NBMs for cancer theranostics is the intravenous (i.v.) via, which poses major challenges in the development of new nanosystems. Once injected, NBMs will interact with a complex mixture of biomolecules naturally present in the bloodstream that can bind on their surface generating a biomolecular corona, which can confer a new biological identity to the NPs, inducing what is called the "corona effect". This is a major concern since the characteristics of the outermost molecular layer are always responsible for the interaction of such "modified NBMs", thus influencing the way they will interact with the biological system, such as the vessel walls, tissues, and organs. Accordingly, the formation of a biomolecular corona can completely change the biological parameters, such as the pharmacokinetics and fate of nanoparticles, now strongly influenced by the biomolecules that are adsorbed on the NPs surface (Corbo et al., 2015). Furthermore, the corona layer can interfere in the biological activity as illustrated by Salvati et al. The group demonstrated that transferrin-conjugated NPs, a glycoprotein known to target transferrin receptors overexpressed in some cancer cell subtypes, can lose the vectoring ability upon adsorption of biomolecules (Salvati et al., 2013).

The corona layer consists of two parts, the hard corona and the soft corona (Figure 3). The former one is comprised of molecules that are strongly bound to the NPs surface and have a slow exchange rate, while the latter one is constituted by more weakly 


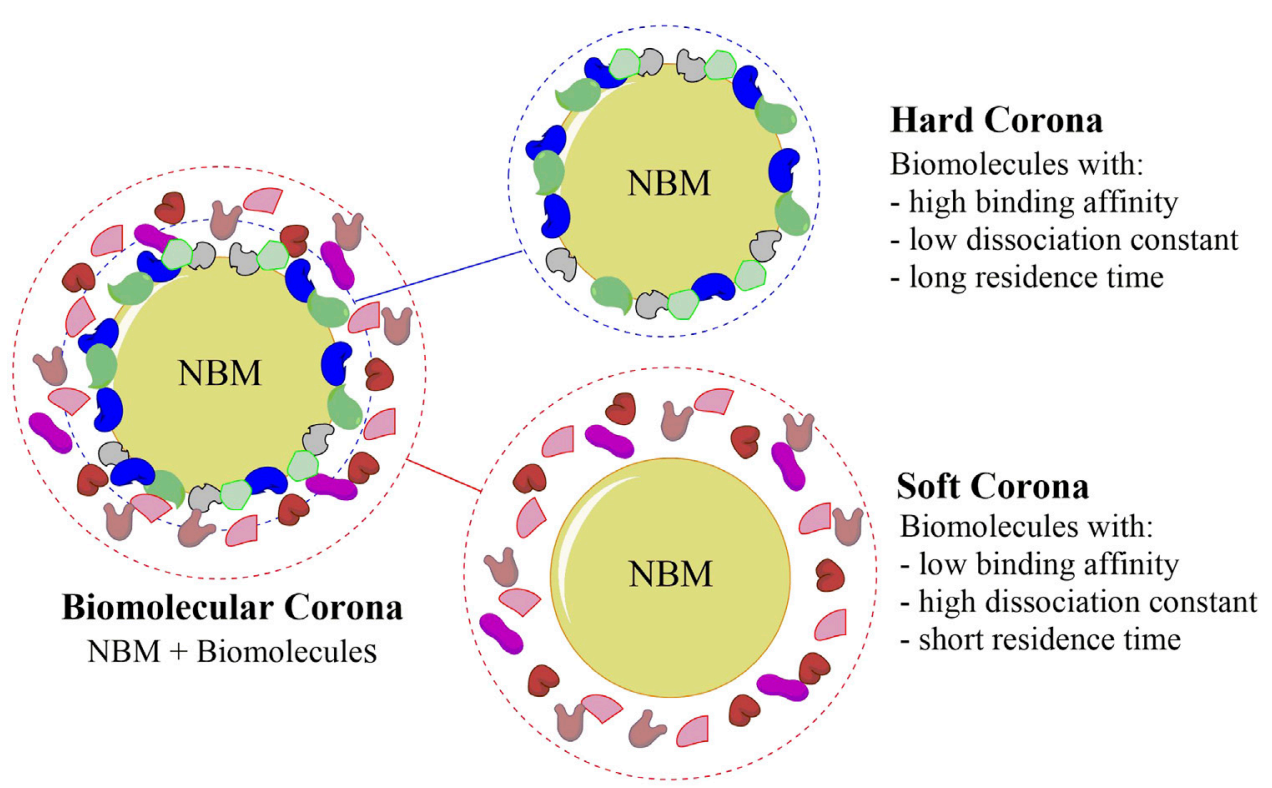

FIGURE 3 | Schematic representation of the biomolecular corona, showing the hard corona and the soft corona, that can confer a new biological identity to nanobiomaterials (NBMs). The hard corona is comprised of strongly bound biomolecules to the NBMs surface, whereas the soft corona is formed by weakly interacting biomolecules.

and dynamically attached biomolecules (Corbo et al., 2015). Ashby et al. showed that the nature of the IO NPs coating layer influences the bonding/dissociation dynamic of the corona. A soft corona is preferentially formed when the hydrophobicity of the NPs surface is increased since proteins with faster exchange rates tend to be adsorbed (Ashby et al., 2014). Furthermore, the corona composition can change the cellular uptake mechanism as demonstrated by Francia et al. in vitro incubating nanoparticles with different amounts of human serum. Similar result was obtained by changing the nanomaterial size or composition (Francia et al., 2019). Accordingly, Papini et al. pointed out that the NP/biomolecules ratio must be an important parameter to be considered since the surface area available for adsorption is proportional to the NP concentration, and a more complex heterogeneous corona is expected as it increases (Papini et al., 2020). These aspects are interesting since the plasma components and respective concentrations can vary significantly among patients and the disease stage, resulting in NPs with biomolecular coronas with different compositions and biological outcomes (Corbo et al., 2017; Sepand et al., 2020). To sum up, the corona effect is dependent on two groups of factors, as proposed by Singh et al. (Singh et al., 2021): 1) material parameters such as NBMs molecular coating, charge, and size, and 2) environmental parameters such as the incubation time, $\mathrm{pH}$, and type and concentration of proteins.

The corona effect has a direct influence on the biological interactions and fate of NBMs in vivo that often cannot be anticipated by in vitro studies, probably due to the difficulties in reproducing such a complex environment. Clearly, however, the formation of hard corona can be controlled/avoided by suitable design of the NBMs' surface chemistry, or by precoating them with specific biomolecules (Singh et al.,
2021). In fact, it has been shown that the corona composition can be controlled by a proper engineering of the conjugated molecular layer. In this way, it is possible to transform an impairing phenomenon into an ally to improve not only the CS but also the circulation time by stealthing them from the immune and clearance systems, while further modulating their interactions with cells (Cai et al., 2020). For instance, Szekeres et al. studied the effect of human plasma on the CS of IO NPs by monitoring their hydrodynamic size as a function of plasma concentration $(0-80 \% \mathrm{v} / \mathrm{v}$ in Tris buffer saline solution). The addition of low concentrations of plasma into non-functionalized (NF) and citrate-coated NPs led to the formation of large aggregates that precipitated out. Nevertheless, at much larger plasma concentrations, CA-NPs did not precipitate out, and their size distribution remained similar to the initial one indicating that they were covered up and stabilized by a biomolecular corona layer (Szekeres et al., 2017). Accordingly, Moya et al. suggested human serum albumin (HSA) as a good candidate to improve the colloidal stability of CA-IO NPs in the human serum, without compromising the NP efficiency as magnetic resonance imaging (MRI) contrast agent. In fact, a compact enough protein corona is formed to increase the digestion time with an acid condition (such as lysosomes in cells), a valuable feature since it would avoid the need of re-administration in case the MRI diagnostic must be repeated (Moya et al., 2019). On the other hand, PEG stealth effect could be related not only to the polymer itself but also to a clusterin-rich associated biomolecular corona (Schöttler et al., 2016). However, there is no enough evidence yet to categorize clusterin as a dysopsonin, a biomolecule that actively suppresses the capture of NPs from bloodstream by the MPS (Papini et al., 2020). A designed peptide that binds to transferrin was especially 


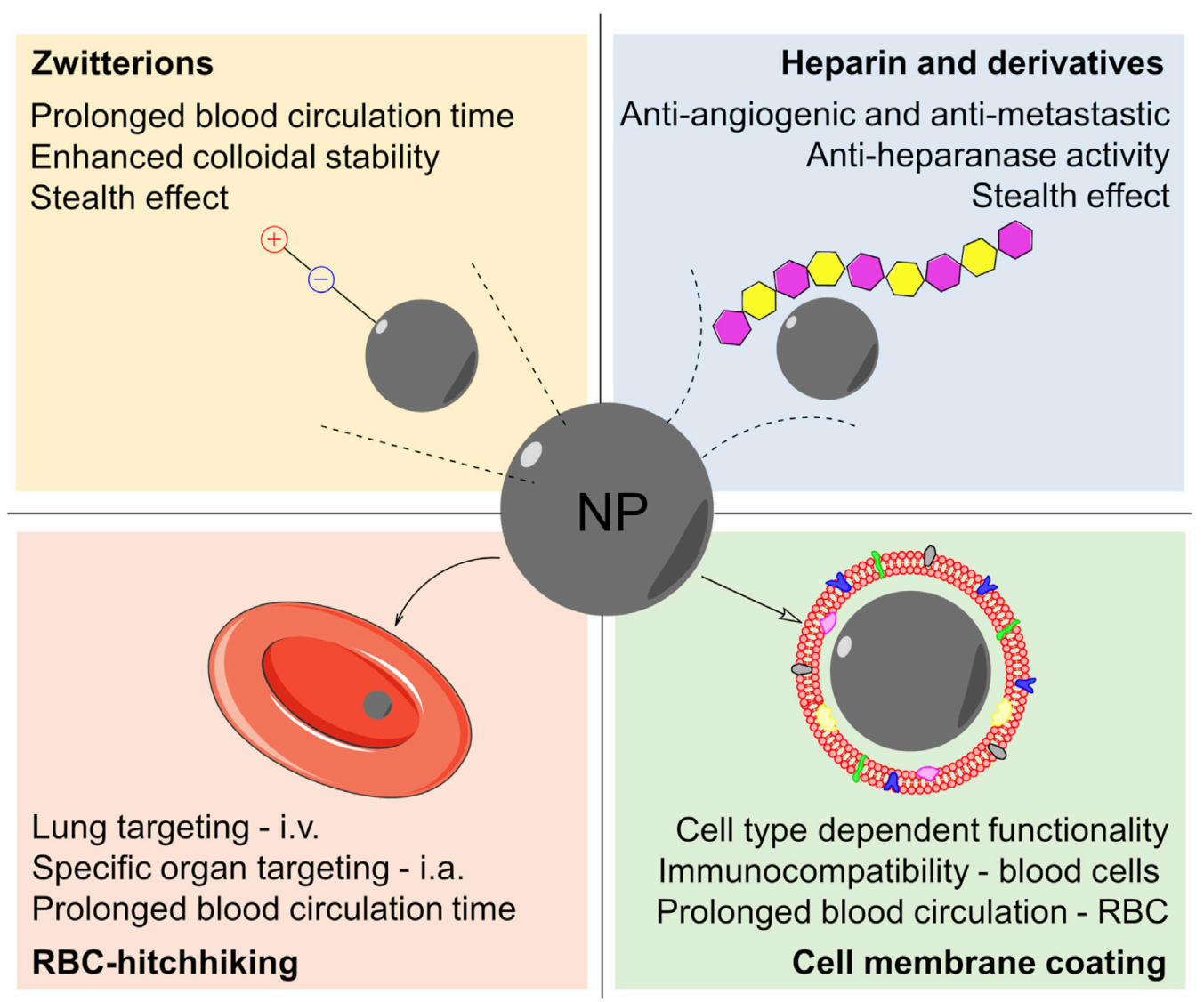

FIGURE 4 | Scheme summarizing the most promising surface chemistry approaches for the preparation of NBMs for cancer theranostics: coating the nanoparticles (NP) with zwitterions, heparin and its derivatives, cell membranes, or red blood cells (RBC) adhesive molecules (RCB-hitchhiking). Also, some of the advantages are listed for each approach. Abbreviations: i.v-intravenous injection via; i.a-intra-arterial injection via.

conjugated on the NPs surface by Santi et al. leading to an increased NP internalization by Mia $\mathrm{Pa}-\mathrm{Ca} 2$, a high transferrin receptor-expressing cell line (Santi et al., 2017), thus demonstrating the possibility of targeting based on proteins recruited as corona layer while Ritz et al. demonstrated that the preincubation of NPs with the specific proteins ApoA4 or ApoC3, or ApoH, can modulate the cellular uptake by decreasing it or increasing it, respectively, in human mesenchymal stem cells (hMSC) model (Ritz et al., 2015).

In short, the formation, composition, and effects of a biomolecular corona layer on biological processes and activities are fundamental aspects that ought to be considered when designing theranostic nanomaterials. Some examples and perspectives were presented here, but it is discussed in more details in the reviews by Pinals et al. and Carrillo-Carrion et al., who have summarized the various techniques for direct and indirect analyses of the corona layer associated with NPs (Carrillo-Carrion et al., 2017; Pinals et al., 2020).

\section{Promising Approaches for Enhancing Biocompatibility and Non-immunogenicity}

Considering the relevance of the conjugated molecular layer and all processes that can change the properties governing the nanoparticles interactions in biological systems, such as the formation of a corona as above-mentioned, promising strategies for NPs surface functionalization have been explored aiming the development of biocompatible, non-immunogenic and stealth NBMs for application in cancer theranostics (Figure 4).

Among them, there are those based on zwitterions, molecular species containing different functional groups with positive and negative charges but overall neutral charge. They are hydrophilic granting good affinity with aqueous media, similarly to PEG. Furthermore, zwitterions tend to inhibit the adsorption of proteins, including opsonins, blood components responsible for the activation of the immune system, thus conferring an effective stealth effect to the nanomaterials, as proposed by Schlenoff (2014). Briefly, the water molecules around the zwitterions are organized in structures resembling those in bulk water, in order to maximize the amount of hydrogen bonds. Consequently, there would be no significant entropy change associated with the rearrangement of water molecules induced by protein adsorption onto a zwitterionic molecular layer. Also, the charges in zwitterionic species are selfcounterbalanced and there is no associated counterion hence making protein adsorption less likely to take place, giving rise to a 
kind of natural antifouling property (Schlenoff 2014). Consistently, Ma et al. compared IO NPs, designed for use as MRI contrast agent, conjugated with PEG, and PEG cysteine (PEG-Cys), a zwitterionic amino acid, which demonstrated a significantly lower tendency to adsorb BSA (Ma et al., 2017). In addition, the uptake of PEG-Cys zwitterionic IO NPs by RAW264.7 murine macrophage cell lines was significantly diminished as compared with conventional NPs. Similar results were reported by Mondini et al. who demonstrated that ZDS-IO NPs were less internalized by HepG2 hepatocarcinoma cell lines than MEEA-coated NPs, a PEGlike carboxylic acid. Accordingly, it was suggested that the lower cellular internalization of zwitterionic NPs might be related to the above-mentioned thermodynamically induced antifouling properties (Mondini et al., 2015).

Another emerging approach to improve the stealthing properties of nanomaterials is by covering them up with biomolecules, such as carbohydrates, lipids, and proteins, as well as cellular components usually found in the blood, thus inhibiting their recognition and clearance by the MPS. This strategy was reviewed in detail by Gulati et al. (2018) so that only some typical examples will be described herein. For instance, among the carbohydrates, heparin (HEP) is a naturally occurring glycosaminoglycan, well known for its anticoagulant properties. Additionally, recent clinical evidence suggested that HEP might also present antimetastatic and antiangiogenic effects, improving the survival rates of cancer patients (Ma et al., 2020). Hence, heparin and its derivatives are quite interesting molecules that were used by Ternent et al. to coat IO NPs that showed a good CS and nuclear spin relaxivity, demonstrating their potential as MRI contrast agents (Ternent et al., 2016). On the other hand, Fazilati designed a magnetic HEP-coated IO NPs loaded with the antitumoral drug cisplatin demonstrating a synergistic effect that enhanced the drug cytotoxicity against CP70 human ovarian cancer cell in vitro (Fazilati, 2014). Also, Groult et al. demonstrated that heparin and its derivatives can have antiheparanase activity when conjugated to IO NPs, not only acting as stealth and stabilizing agent. Heparanase is a protein expressed in tumor microenvironment and participates in angiogenesis. Hence HEP-IO NP was proposed as an MRI theranostic agent (Groult et al., 2017). More recently, HEP-IO NPs doped with the ${ }^{68} \mathrm{Ga}$ radionuclide were demonstrated to be suitable for dualmode PET/MRI theranostics (Groult et al., 2021).

Blood circulating cells are interesting shuttles and camouflage for NPs since they are not recognized as foreign bodies and thus do not activate the immune system. Accordingly, erythrocytes (red blood cells, RBCs) have been explored in two ways: 1) by the so-called "RBC-hitchhiking" approach and 2) based on the use of its cellular membrane as camouflage. RBC-hitchhiking NPs were explored for the first time by Chambers and Mitragotri, inspired by the strategy utilized by the mammalian pathogens Haemobartonella and Eperythrozoonosis which can remain in blood circulation for several weeks bound on RBCs (Chambers and Mitragotri, 2004). Zelepukin et al. did a systematic study to understand the interaction of magnetic IO NPs with RBCs assessing parameters such as size, surface chemistry, corona effect, in vitro cytotoxicity, in vivo pharmacokinetics, and biodistribution. Thus, it was demonstrated that $100-\mathrm{nm}$ large chitosan-coated NPs were suitable for RBC hitchhiking and delivery of doxorubicin to lung cells for effective treatment of B16-F1 melanoma cell line metastasis in the C57BL/6 mice model. The effectiveness of this strategy has been attributed to the mechanism of delivery, which relies on the ex vivo adsorption of NPs on RBCs, followed by intravenous injection and detachment of NPs when passing through fine capillaries due to the shear stress against the walls (Anselmo et al., 2013; Zelepukin et al., 2019). In an elegant work, Brenner et al. demonstrated that it is further possible to target specific organs by RBC-hitchhiking strategy via intra-arterial administration (Brenner et al., 2018). Excellent reviews on the use of blood cells hitchhiking strategy for the development of advanced drug delivery systems (DDS) for biomedical applications have also been published (Anselmo and Mitragotri, 2014; Villa et al., 2016). In addition, the RBC membrane can be utilized to coat NPs after isolation and suitable treatment, making them invisible to the immune system. In fact, the presence not only of naturally occurring membrane lipids but also of proteins, receptors, and other biomolecules associated to the cell membrane avoids their recognition and consequent activation of the immune response. Rao et al. showed that IO NPs coated with RBCderived cell membrane exhibited a superior performance remaining in circulation for a longer period in comparison with NPs conjugated with PEG (Rao et al., 2015). Similar results were reported by Ren et al. and by Rao et al. who further demonstrated that RBC-membrane-coated IO NPs could be used as efficient theranostic agents (Ren et al., 2016; Rao et al., 2017). Furthermore, this strategy is not limited to RBCs, as summarized by Fang et al., but can be extended to the membrane of other cell types; thus, it has been possible to modulate the NPs properties for specific applications (Fang et al., 2018).

\section{Co-adjuvant Molecules}

The impact of the NPs surface chemistry in the CS and in the interaction with biomolecules and cells present in the bloodstream was addressed so far. In this section, we will briefly discuss about co-adjuvant molecules that grant additional functionalities to the NBMs (Figure 1).

\section{Therapeutic Agents}

In cancer theranostics, the nanotechnology approach confers new prospects for the usage of antitumoral drugs. Most therapeutic agents are hydrophobic molecules incompatible with aqueous biological media. This characteristic restrains their solubility and therefore their bioavailability, a critical parameter that defines the drug dosage and possible undesirable side effects. Accordingly, nanotechnology has been applied to overcome those limitations by exploring liposomal and nanocapsule formulations as drug nanocarriers, significantly altering the pharmacokinetics, pharmacodynamics, and toxicological effects (Apolinário et al., 2020; Deda et al., 2020). These nanocarriers can enhance the apparent solubility and bioavailability of drugs, conferring stealth effect and safety, reducing systemic adverse effects, and even 
enhancing the cellular uptake. Another possibility to improve the pharmacological parameters of a drug is by combining it with specially designed nanoparticles. In this case, their surface chemistry must be engineered in such a way to make them highly dispersible and colloidally stable in aqueous media, even though with a significant hydrophobic load (Romano, et al., 2020). For instance, we have demonstrated that by coconjugating methotrexate, an antitumoral drug, with the stabilizing agents, glycerol phosphate and phosphorylethanolamine onto IO NPs, it is possible to get an NBM capable to decrease the IC50 of MCF-7 breast cancer cell line in ten folds (Deda et al., 2021).

In addition, Jeon et al. and Augustin et al. have demonstrated the potential of IO NPs conjugated with paclitaxel and doxorubicin (Dox) for the treatment of some cancer subtypes. Furthermore, the polymer matrix of the molecular coating layer of NPs can be used to load and deliver drugs (Augustin et al., 2016; Jeon et al., 2019). For instance, Liu et al. incorporated cisplatin on $\mathrm{TiO}_{2}$ NPs coated with hyaluronic acid (HA), a polysaccharide that acts not only as a stabilizing agent but the matrix for drug loading. Moreover, HA has a high affinity for $\mathrm{CD} 44$, a receptor overexpressed in some cancer cell lines. Hence, cisplatin-loaded $\mathrm{TiO}_{2} @ \mathrm{HA}$ nanoparticles were tested in the neoadjuvant chemotherapy of ovarian cancer (Liu et al., 2015).

\section{Targeting Agents}

When engineering a DDS, it is fundamental that the NBMs have a high selectivity for the therapeutic site, or in other words, for the cells and tissues to be treated (Wilczewska et al., 2012). This can be achieved by the conjugation of appropriate targeting agents, such as HA, leading to their recognition, interaction, and concentration in the areas of therapeutic interest, where the drug ought to be released to provide its beneficial effects ( $\mathrm{Gu}$ et al., 2007). This process of concentration in selected sites, called vectoring or targeting, is one of the most fundamental requirements and challenges to overcome when designing NBMs for both diagnostics and treatment, including by multimodal strategies. Several classes of molecules have been studied as targeting agents for the preparation of NBMs for cancer theranostics. The selective concentration of antitumoral compounds by using drug delivery nanosystems may occur in two ways: 1) passively by enhanced permeability and retention, EPR, when the accumulation of nanoparticles in solid tumors is consequence of the abnormal physiology of the newly formed vessels (Xie et al., 2010), or 2) actively, when the process is driven by ligands on the NPs surface that is able to recognize and interact specifically with tumor cells or structures, such as vitamins, aptamers, polysaccharides, peptides, and antibodies (Xie et al., 2010; Yoo et al., 2019). The implementation of this characteristic to bioactive nanoparticles enables the administration of much lower doses since they will be delivered in the right place for a localized and effective action, as expected for a safer therapy with none or minimal side effects. Furthermore, targeting is also a key property for the realization of efficient and safer platforms for molecular diagnostics. Finally, it is interesting to mention that a new class of targeting agents is emerging. They are based on naturally occurring extracellular vesicles (EV) thus imparting all the advantages of previously mentioned cell-membrane-derived NPs coatings, especially stealthing for longer circulation time. EVs function in intercellular communication, and hence, they present a complex variety of interesting components embedded in the cellular membrane for specific recognition of given structures (Piffoux et al., 2019). Thus, EVs can be used as Trojan horses for loading NPs and/or therapeutic agents, to produce theranostic agents for cancer, as illustrated by the elegant work of Silva et al. EVs derived from human macrophages THP1 cell line were loaded with magnetic IO NPs and photosensitizers, and tested in vivo for MRI diagnostic and PDT treatment, two techniques that will be discussed later on in this review (Silva et al., 2013). For more details on this novel approach, we recommend the review article by Piffoux et al. (2019), Walker et al. (2019).

\section{Radiotracers}

Another class of co-adjuvant molecules explored in cancer theranostics is the radiotracers, which comprises radionuclides that emit high-energy photons and particles used for radiotherapy and/or imaging diagnosis (Hong et al., 2009). In particular, radionuclides that are $\gamma$ or $\beta+$ particle emitters are utilized in the imaging techniques by single-photon emission computed tomography (SPECT) and positron emission tomography (PET), respectively, while the ones that are $\alpha$ or $\beta$ - particle emitters, or Auger electron emitters, are commonly used for therapy. The nanoparticles surface can be used as an anchoring site for these radionuclides which can be directly adsorbed or conjugated by utilizing chelating ligands (Lamb and Holland, 2018). This way, the NPs act as radiotracer carriers and can be employed in radionuclide-based imaging techniques, as illustrated by de Rosales et al., in which IO NPs were radio-labeled with ${ }^{99} \mathrm{~m} \mathrm{Tc}$, a classical radionuclide used in SPECT, through a bisphosphonate-based chelator (de Rosales et al., 2011). It is interesting to observe that bisphosphonate-based chelators also can be conjugated on $\mathrm{TiO}_{2}$ NPs, demonstrating their potential as nanocarriers of radiotracers and radiopharmaceuticals (Řehoř et al., 2011). For example, Cędrowska et al. have proposed the use of $\mathrm{TiO}_{2} \mathrm{NPs}$ for radiotherapy based on ${ }^{225} \mathrm{Ac}$, an alpha-particle emitter radionuclide (Cędrowska et al., 2018). Also, we have investigated IO NPs as a multifunctional platform for dualmode diagnostic of breast cancer in in vivo models by conjugating the Traztuzumab antibody as a targeting agent, and simultaneously attaching pentetic acid (DTPA) as a chelating agent for coordination of ${ }^{99 \mathrm{~m}} \mathrm{Tc}$ and ${ }^{68} \mathrm{Ga}$. The resultant NBMs were successfully concentrated on a breast cancer model xenografted on the back of Balb/c nude mice (de Souza Albernaz et al., 2018).

\section{NANOBIOMATERIALS BASED ON TITANIUM DIOXIDE NANOPARTICLES}

Titanium dioxide is a semiconductor material with favorable physico-chemical properties for application in white paint pigments and sunscreens, due to its high chemical stability 
and interesting optical properties, especially the high refractive index and capacity to absorb UV light, and reflect/scatter visible light (Antoniou et al., 2008). On the other hand, charge separation can be induced by photoexcitation exploring its semiconductor properties, generating a high-energy hole in the valence band that has been extensively explored to promote photodegradation processes, for example, of contaminants in water. The concomitantly generated electron in the conduction band also can be used in reduction processes despite its relatively low energy.

$\mathrm{TiO}_{2}$ nanoparticles are generally produced on a large scale by reaction of titanium tetrachloride and water, a high throughput, and efficient method, but more refined techniques are generally necessary for the preparation of NPs for biomedical applications. There are several methods available for the synthesis of $\mathrm{TiO}_{2} \mathrm{NPs}$, such as chemical deposition methods (Seifried et al., 2000; Oh and Ishigaki, 2004), electrophoretic deposition methods (Nyongesa and Aduda, 2017), spray pyrolysis (Okuya et al., 2004), sonochemical and microwave-assisted methods (Zhu and Chen, 2014), hydro or solvothermal methods (Kim et al., 2003; Feng et al., 2005), sol-gel methods (Oskam et al., 2003), and template-assisted methods (Jiang et al., 2007; Yuan et al., 2013). The most used among all are the sol-gel, the hydro and solvothermal, and the template-assisted methods, given the simplicity allied to improve the control on the size and shape combined with colloidal stabilization and functionalization strategies.

The widespread application of $\mathrm{TiO}_{2} \mathrm{NPs}$ as a white pigment in cosmetic formulations, such as sunscreens, powders, and eyeshadows, is related to their high availability allied to low toxicity. However, it is important to notice that in those cases, the material is applied on the skin, a quite stringent barrier (Dréno et al., 2019). The situation changes significantly when intravenous or other internal applications are considered since it involves the administration of nanomaterials directly in the blood or tissues as discussed in the previous topics. In this context, the toxicity becomes very dependent on factors such as size, morphology, and surface chemistry of nanoparticles. Hence, toxicological studies are essential for the evaluation of the biocompatibility, biodistribution, clearance, and possible toxicity. Aula et al. have systematically described the in vitro and in vivo assays to assess the toxicological effects of NBMs (Aula et al., 2015). Ideally, both in vitro and in vivo experiments are necessary for the evaluation of the toxicological parameters in a complementary way. As mentioned in the previous topics, the in vitro and the in vivo conditions differ considerably due to the biological medium, biomolecules concentration, shear stress, dynamic flow, the corona effect, among other factors that affect the NPs stability and aggregation process, and ultimately the biological interactions and fate. Accordingly, biocompatible NBMs are achieved when they exert their functionality without showing significant adverse toxic effects to the organism.

In fact, the nature of the molecular species conjugated on NPs surface may be used to control the eventual toxic effects, thus adjusting it to the requirements of a given application. For instance, Thevenot et al. showed that the cytotoxic effects on cancer cells were dependent on the molecules conjugated on the
NBMs as well as the cell line. Uncoated $\mathrm{TiO}_{2} \mathrm{NPs}$ reduced micederived LLC lung carcinoma viability considerably, but the micederived B16F1 skin melanoma viability was not affected at a concentration as high as $10 \mathrm{mg} / \mathrm{ml}$. Interestingly, the cytotoxicity on LLC cells was decreased upon conjugation of polymers to the NPs surface (Thevenot et al., 2008). Uncoated $\mathrm{TiO}_{2}$ NPs were shown to aggregate in $0.9 \%$ saline solution and accumulate mainly in the liver, spleen, and lungs upon i.v. administration in rats, but without toxic effects at a dose of $7.7-9.4 \mathrm{mg} / \mathrm{kg}$ (Elgrabli et al., 2015). Another critical aspect during the modification of the molecular outer layer is ensuring the colloidal stability of the suspensions since aggregation processes irreversibly compromise their interaction properties with biological systems (Albanese and Chan, 2011). Aggregation may even compromise the NPs functionality, for example, attenuating the photodynamic therapy efficiency (Kamps et al., 2013). In order to enhance the NP stability and to reduce the clearance by MPS and the accumulation in the liver, spleen, and kidney of mice, Li et al. utilized RBC-derived membranes to coat mesoporous $\mathrm{TiO}_{2}$ NPs. This strategy enabled an NBM able to accumulate more effectively in MCF-7 tumor in vivo model (Li S et al., 2021).

The semiconductor properties of $\mathrm{TiO}_{2}$ NPs conjugated with suitable molecules are being explored in therapeutic approaches such as photodynamic therapy, which is considered economical, more effective, and less invasive than conventional approaches, reducing the need of repeated and prolonged treatments. PDT is recommended primarily for oral, head, and neck cancer although the possibility of treating other subtypes is being currently explored (dos Santos et al., 2019). PDT combines the interaction between a photosensitizer (PS) and light, generally in the presence of molecular oxygen, which is excited to a very reactive singlet state, the active species (Kou et al., 2017). Most photosensitizers exhibit autofluorescence, which makes easier to track them when concentrated in specific parts of the body requiring treatment, but are activated only when combined with light of suitable wavelengths thus imparting good control on the PDT treatment (Usuda et al., 2007). In fact, despite the systemic application of PS, the production of reactive oxygen species (ROS), responsible for cells death, is circumvented only to the local where they were photoexcited, greatly reducing the toxicity to normal tissues (Wang et al., 2011). $\mathrm{TiO}_{2}$ NPs, most frequently associated with photoactive organic dyes such as porphyrins and phthalocyanines, are being explored as theranostic agents against various cancer subtypes (Yurt et al., 2018; Shi et al., 2020).

Nanobiomaterials based on $\mathrm{TiO}_{2}$ NPs have also been investigated for cancer therapy, but in a modest extent when compared with IO NPs. For instance, the combination of $\mathrm{TiO}_{2}$ NPs with antitumoral agents has been proposed as an efficient drug delivery platform for chemotherapy (Chen et al., 2017). Different drug release mechanisms such as $\mathrm{pH}$-triggered (Wang et al., 2019) and irradiation-triggered delivery (Li et al., 2009), among others, have been explored in that context. The release of drugs triggered by a stimulus grants a more effective and controlled delivery of bioactive molecules to tumor cells in contrast to healthy cells (Wang et al., 2016; Raja et al., 2020). 
This is a highly pursued condition since the amount of chemotherapeutic agent used in the treatment can be significantly decreased, while maintaining the desired pharmacological effects, thus minimizing the occurrence of adverse side effects.

The perspectives of such NBMs in cancer therapy are better illustrated by exploring the combination of $\mathrm{TiO}_{2} \mathrm{NPs}$ with Dox, a well-established antitumoral drug used against several cancer subtypes to block cellular replication and tumor growth. In addition, it is known to produce free radical species causing irreversible damage to biomolecules and consequent cell death (Tacar et al., 2013). Nevertheless, Dox has nonspecific action, and its usage leads to undesired side effects when devoid of a targeted delivery system. Hence, its combination with NPs was expected to reduce the cytotoxic effects to healthy tissues, while maintaining or enhancing the efficacy against cancer cells, as confirmed by Du et al. who presented exciting in vitro and in vivo results using MDA-MB231-GFP-fLuc breast cancer cells as a model. Dox loaded onto PEGcoated $\mathrm{TiO}_{2}$ NPs showed improved antitumoral efficiency with minimal side effects. Such results were attested by the absence of histological changes and minimal weight loss by the test animals suggesting no significant adverse systemic effects, thus indicating that $\mathrm{TiO}_{2}$-based nanocarriers can increase the chemotherapeutic effects of doxorubicin in vivo (Du et al.,2015).

Several works reported the combination of doxorubicin with a PDT photosensitizer aiming to increase the cytotoxic effects toward cancer cells (Zeng et al., 2015; Tong, et al., 2017; Chen et al., 2017; Flak et al., 2017). Flak et al. (2017) presented two theranostic $\mathrm{TiO}_{2}$-based nanoagents obtained by conjugation of zinc phthalocyanine and Dox. These NBMs were able to penetrate HeLa 3D-spheroid cells and impart enhanced cytotoxicity against fibroblast MSU-1.1 model cells. Furthermore, their potentiality for bioimaging by confocal fluorescence microscopy was demonstrated. A similar strategy was also explored in an elegant work by Zeng et al. (2015), who designed a Janus nanocomposite of rare-earth NaYF4:Yb/Tm and $\mathrm{TiO}_{2}$, which act as an inorganic photosensitizer, loaded with Dox and folic acid (FA), for simultaneous PDT and drug delivery based on upconversion luminescence (UCL). Rare-earth-based nanomaterials enable an alternative PDT approach due to the UCL property. Upon excitation with near-infrared light (NIR), the rare-earth nanoparticle emits UV radiation that is absorbed by the $\mathrm{TiO}_{2}$ NPs producing high-energy electrons and holes capable of generating ROS. This is one of the few examples of nanomaterials using an inorganic PS to activate a semiconductor active component. The nanocomposite was tested with breast cancer cell lines, demonstrating low cytotoxicity and improved efficacy against multidrug-resistant MCF-7/ADR cells as compared to free Dox in in vitro assays. This result was confirmed in vivo by using nude mice model, which presented no alteration in the major organs 15 days post-intravenous administration of FA-NPs-Dox in comparison with the controls PBS, FA-NPs, and free Dox. A similar approach was proposed by Chen et al. and Tong et al., who proposed nanoparticles with rare-earth core and hollow mesoporous $\mathrm{TiO}_{2}$ shell, conjugated with PEG and 3-aminopropyltriethoxysilane, and loaded with Dox, as $\mathrm{pH}$-dependent DDS and simultaneous NIR-triggered PDT nanoagents (Chen et al., 2017; Tong, et al., 2017). According to the in vitro MTT assays, such a dual therapy approach enhanced the cytotoxicity and promoted a significant reduction in HeLa cells viability when compared to the drug delivery therapy alone. In short, nanoagents based on $\mathrm{TiO}_{2}$ NPs combining chemotherapy with PDT, by concomitant local delivery of an antitumoral agent, such as Dox, with image diagnostic by fluorescence, are very promising NBMs to improve the treatment of cancer.

At this point, it is important to note that some Dox drug delivery nanosystems were co-conjugated with folic acid as a targeting agent (Tong, et al., 2017; Chen et al., 2017). Folic acid is a vitamin related to the DNA nucleic bases synthesis, essential for survival and growth of normal cells as well as of tumor cells in rapid proliferation. For this reason, folate receptors are overexpressed in the plasmatic membrane of tumor cells making them interesting targets (Fernández et al., 2018). Hence, folic acid can be explored to actively vectoring nanobiomaterials for diagnostic, drug delivery, and theranostic of diseases such as breast and ovarian carcinoma, among others. The incorporation of folic acid was shown to increase the selectivity inducing their concentration in MCF-7, SKOV3, and HeLa tumor cells in comparison with normal cells, thus demonstrating its effectiveness in targeting strategy. In another vectoring approach, Sette et al. had presented a novel antibody for conjugation with $\mathrm{PEG}-\mathrm{TiO}_{2} \mathrm{NPs}$, and targeting $\mathrm{Kv} 11.1$ potassium channel, expressed on the plasma membranes of pancreatic ductal adenocarcinoma cells (Sette et al., 2013). Furthermore, Jana et al. presented an interesting approach for the dual co-conjugation of biomolecules on $\mathrm{TiO}_{2} \mathrm{NPs}$ by multifunctionalizing them with tris-(nitrilotriacetic acid) (Tris-NTA) and biotin anchoring sites for oligo-histidine and avidin-modified biomolecules, respectively (Jana et al., 2013). By using this approach, a vast class of targeting biomolecules such as antibodies can be conjugated to $\mathrm{TiO}_{2}$ NPs generating NBMs aiming for specific diseases.

The works presented so far intended to illustrate the possibilities of application of $\mathrm{TiO}_{2} \mathrm{NPs}$ and how the results can be influenced by the composition and the size, as well as the molecules intentionally conjugated on the surface, or unintendedly adsorbed such as due to the formation of a corona. Of course, the variety of studies and approaches that can be found in the recent literature involving $\mathrm{TiO}_{2}$ NBMs spams a much broader scope, and the examples presented below refer only to those published and consolidated in the last two decades. For example, it has been consistently demonstrated that $\mathrm{TiO}_{2}$ NPs have no significant tendency to penetrate the gastrointestinal tract (Janer et al., 2014; Bachler et al., 2015). On the other hand, histopathological investigations for almost three months indicated that when i.v. administered, they tend to accumulate mainly in the liver, but also in the spleen, lungs, and kidneys in minor extent (Fabian et al., 2008; Geraets et al., 2014). A complementary work by Xie et al. showed that the main route of elimination of titanium dioxide-based nanomaterials is via renal excretion (Xie et al., 2011), a quite favorable route. Finally, the agglomeration of nanoparticles is dependent on several factors, such as $\mathrm{pH}$ and ionic strength, but also concentration since saturation can be reached leading to agglomeration. Nevertheless, this is a problem that can be solved by proper choice of the molecules conjugated on the NPs surface. In fact, there are bright perspectives for the development of efficient $\mathrm{TiO}_{2}$-based nanoagents for 
TABLE 1 | Examples of $\mathrm{TiO}_{2}$-based nanomaterials and its application in cancer theranostics.

\begin{tabular}{|c|c|c|c|c|c|c|c|c|}
\hline \multirow[t]{2}{*}{ Applications } & \multirow[t]{2}{*}{ Material } & \multirow{2}{*}{$\begin{array}{l}\text { Size } \\
(\mathrm{nm})\end{array}$} & \multirow[t]{2}{*}{ Shape } & \multirow{2}{*}{$\begin{array}{l}\text { Stabilizing } \\
\text { agent }\end{array}$} & \multirow{2}{*}{$\begin{array}{l}\text { Co-adjuvant } \\
\text { agents }\end{array}$} & \multicolumn{2}{|c|}{ Biological studies } & \multirow[t]{2}{*}{ Reference } \\
\hline & & & & & & $\begin{array}{l}\text { In Vitro: Cell line } \\
\text { (cytotoxic } \\
\text { concentration) }\end{array}$ & $\begin{array}{l}\text { In Vivo: Animal } \\
\text { model (toxic } \\
\text { concentration) }\end{array}$ & \\
\hline $\begin{array}{l}\text { Chemodynamic } \\
\text { therapy/SDT }\end{array}$ & $\begin{array}{l}\text { Fe-doped } \\
\text { anatase } \mathrm{TiO}_{2}\end{array}$ & 2.49 & ND & PEG & - & $\begin{array}{l}\text { HUVEC } \\
\text { (N.C. } 80 \mu \mathrm{g} \mathrm{TV} / \mathrm{ml}) \\
\text { 4T1 }(80 \mu \mathrm{g} \mathrm{Ti} / \mathrm{ml})\end{array}$ & $\begin{array}{l}\text { Balb/c Mice } \\
\text { (N.T. } 40 \mathrm{mg} \mathrm{Ti} / \mathrm{kg} \text { ) }\end{array}$ & Bai et al. (2020) \\
\hline \multirow[t]{3}{*}{ Drug Delivery } & Anatase $\mathrm{TiO}_{2}$ & $30-60$ & Sphere & Alginate & $\begin{array}{l}\text { Temozolomide } \\
\text { (TMZ) }\end{array}$ & $\begin{array}{l}\text { SH-SY5Y } \\
(100 \mu g \text { TMZ-NP/ml) }\end{array}$ & $\begin{array}{l}\text { Balb/c Nude } \\
\text { Mice (T.N.E.) }\end{array}$ & Zhao et al. (2021) \\
\hline & Anatase $\mathrm{TiO}_{2}$ & $5-25$ & Sphere & - & $\begin{array}{l}\text { Erlotinib, } \\
\text { Vorinostat }\end{array}$ & $\begin{array}{l}\text { MCF-7/10A } \\
\text { (1 mg drug loaded NP/ml), } \\
\text { MDA-MB-231 } \\
\text { (1 mg drug loaded NP/ml), WISH } \\
\text { (1 mg drug loaded NP/ml) }\end{array}$ & - & $\begin{array}{l}\text { Abdel-Ghany et al. } \\
(2020)\end{array}$ \\
\hline & Anatase $\mathrm{TiO}_{2}$ & $\begin{array}{l}\text { Pore: } \\
187.81 \\
\text { Length: } \\
1236\end{array}$ & NTB & Polyethylenimine & $\begin{array}{l}\text { Camptothecin } \\
(\mathrm{CPT}) \\
\text { Ferric NPs }\end{array}$ & $\begin{array}{l}\text { HeLa } \\
(50 \mu g \text { CPT-NTB/ml) }\end{array}$ & - & $\begin{array}{l}\text { Kafshgari et al. } \\
\text { (2019) }\end{array}$ \\
\hline \multirow[t]{2}{*}{$\begin{array}{l}\text { Photodynamic } \\
\text { therapy }\end{array}$} & $\begin{array}{l}\mathrm{N} \text {-doped } \\
\text { anatase } \mathrm{TiO}_{2}\end{array}$ & $20-120$ & Sphere & - & - & 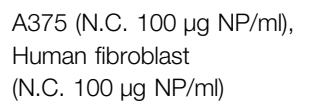 & - & $\begin{array}{l}\text { Mohammadalipour } \\
\text { et al. (2020) }\end{array}$ \\
\hline & $\begin{array}{l}\text { Anatase, } \\
\text { rutile and } \\
\text { amorphous } \\
\mathrm{TiO}_{2}\end{array}$ & $5-1000$ & NA & Transferrin & - & - & $\begin{array}{l}\text { Balb/c } \\
\text { Mice (T.N.E.) }\end{array}$ & Lane et al. (2020) \\
\hline \multirow[t]{2}{*}{$\begin{array}{l}\text { Photothermal } \\
\text { therapy }\end{array}$} & Anatase $\mathrm{TiO}_{2}$ & $10-25$ & Sphere & PEG & - & - & $\begin{array}{l}\text { Balb/c } \\
\text { Mice (T.N.E.) }\end{array}$ & $\begin{array}{l}\text { Behman et al. } \\
\text { (2018) }\end{array}$ \\
\hline & $\mathrm{TiO}_{2}$ & $5-10$ & Sphere & RBC membrane & Au nanorods & 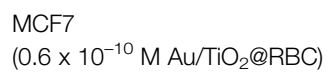 & - & Li and Zhang (2020) \\
\hline Radiotherapy & $\begin{array}{l}\text { Anatase } \mathrm{TiO}_{2} \\
\text { and } \mathrm{TiO}_{x}\end{array}$ & 50 & Sphere & Polyacrylic acid & $\mathrm{H}_{2} \mathrm{O}_{2}$ & BxPC3 (0.895 mg NP/ml) & - & Morita et al. (2021) \\
\hline \multirow[t]{2}{*}{$\begin{array}{l}\text { Sonodynamic } \\
\text { therapy }\end{array}$} & $\begin{array}{l}\text { C-doped } \\
\text { anatase } \mathrm{TiO}_{2}\end{array}$ & $100-200$ & Sphere & Glucose & - & $\begin{array}{l}\text { L292 } \\
\text { (15 mg NP/ml), } \\
\text { 4T1 (15 mg NP/mL) }\end{array}$ & $\begin{array}{l}\text { Balb/c } \\
\text { Mice (T.N.E.) }\end{array}$ & Yang et al. (2020) \\
\hline & Anatase $\mathrm{TiO}_{2}$ & 200 & Sphere & $\begin{array}{l}\text { Polymeric } \\
\text { phenyboronic } \\
\text { acid }\end{array}$ & Dox & $\begin{array}{l}\text { MCF7 (2.5 } \mu \mathrm{M} \text { Dox-NP), } \\
\text { MDA-MB-231 ( } 2.5 \mu \mathrm{M} \text { Dox-NP), } \\
\text { RBCs ( } 2.5 \mu \mathrm{M} \text { Dox-NP) }\end{array}$ & $\begin{array}{l}\text { Balb/c Mice (N.T. } \\
3 \text { mg Dox-NP/kg) }\end{array}$ & Kim et al. (2020) \\
\hline
\end{tabular}

Abbreviations: Dox, doxorubicin; NA, nanoaggregate; N.C., no cytotoxicity observed; ND, nanodot; NP, nanoparticle; N.T., no toxicity observed in major systemic organs; NTB, nanotube; PEG, polyethylene glycol; RBC, red blood cells; SDT, sonodynamic therapy; T.N.E., in vivo toxicity was not evaluated.

diagnostic and treatment of cancer, as presented in Table 1, where examples are listed according to the type of nanoparticle, the stabilizing and/or targeting agents, the in vitro or in vivo models, and possible applications in oncological therapy.

\section{NANOBIOMATERIALS BASED ON IRON OXIDE NANOPARTICLES}

Iron oxide can be found as several polymorphs, being hematite $\left(\alpha-\mathrm{Fe}_{2} \mathrm{O}_{3}\right)$ the thermodynamically most stable one, along with magnetite $\left(\mathrm{Fe}_{3} \mathrm{O}_{4}\right)$ and maghemite $\left(\gamma-\mathrm{Fe}_{2} \mathrm{O}_{3}\right)$. Magnetite and maghemite exhibit interesting magnetic as well as bonding properties for the preparation of functional nanomaterials, thanks to the possibility of easy conjugation of many molecular species on the surface, including biomolecules (Chouhan et al., 2021). More recently, the semiconductor properties of hematite have been more intensely explored for application in photo-driven processes, such as photodecomposition of contaminants and water splitting, as an alternative to $\mathrm{TiO}_{2}$ (Mishra and Chun, 2015). Nevertheless, probably, nanomaterials based on magnetite and maghemite are 
among the most extensively studied ones for biomedical applications, especially given to their high biocompatibility and abundance allied to the intrinsic superparamagnetic and magnetic hyperthermia properties. The superparamagnetism is observed when the core is smaller than a specific critical size, below about $16 \mathrm{~nm}$ for maghemite, yielding superparamagnetic IO NPs (SPIONs). It is important to point out that superparamagnetic materials present no magnetic remanence and coercivity in the absence of an external magnetic field. Furthermore, the magnetic moments of these nanoparticles are thermally randomized resulting in the absence of any magnetic attraction between them, a very convenient feature for biomedical applications (Gyergyek et al., 2017). Magnetite and maghemite belong to the class of materials called ferrites and mixed ferrites that can be prepared by replacing the iron(II) ions in tetrahedral holes of inverse spinel structure by metal ions such as copper(II), nickel(II), cobalt(II), zinc(II), manganese(II), barium(II), and strontium(II) to get similar magnetic materials, whose nanoparticles also can be classified as SPIONs (Laurent et al., 2008; Melo et al., 2021). Accordingly, all such materials can be applied for the development of nanoagents for cancer diagnosis and therapy, but we should be aware that they can exhibit much larger toxicity than the ones solely based on iron.

There are several methods for the preparation of iron oxidebased nanomaterials but some of them are recurrent in the literature: hydrothermal reactions (Gyergyek et al., 2017), solgel synthesis (Lemine et al., 2014), microemulsion method (Zhang et al., 2010), and sonochemical reactions (Dolores et al., 2015). However, in the case of magnetic nanoparticles, the chemical co-precipitation from iron salts (Martínez-Mera et al., 2007; LaGrow et al., 2019) and the thermal decomposition methods (Guardia et al., 2010; EscodaTorroella et al., 2021) are among the most popular given their simplicity. Briefly, in thermal decomposition, the IO NPs are prepared from organometallic precursors at high temperatures, in a nonaqueous solvent. This technique yields magnetic nanoparticles with narrow size distribution, high crystallinity, and controlled morphology (Wu et al., 2015; Roca et al., 2019). However, co-precipitation is the most conventional method, in which a mixture of ferrous and ferric ions is reacted with a strong base (Wu et al., 2015). In all cases, several contaminants can be present in the reaction mixture, and purification methods such as ultracentrifugation (Sjögren et al., 1997; Carney et al., 2011), size exclusion chromatography (Strable et al., 2001), magnetic filtration (Babes et al., 1999), or flow field gradient (Hassan et al., 2008) are necessary to remove them. Among the possible contaminants, there are salts, decomposition byproducts, and eventual free iron ions and nonmagnetic particles formed in the reaction. Those methods also can be used to select and narrow the size distribution, especially to exclude larger aggregated particles.

Toxicological studies, in vitro and in vivo, provide important insights about the toxicity and are fundamental to evaluate the biocompatibility of the NBMs. Prodan et al. demonstrated that IO NPs did not have cytotoxic effects on HeLa cells even at concentrations as high as $30 \mu \mathrm{g} / \mathrm{ml}$, showing no morphological changes in histopathological analysis after intraperitoneal injection in concentration up to $1.4 \mathrm{mmol} / \mathrm{kg}$ in Brown Norway rats (Prodan et al., 2013). But IO NBMs showed different biological responses depending on the size and the surface chemistry. Feng et al. showed that smaller PEG-coated NPs exhibited much lower in vitro cellular uptake than polyethylenimine-coated ones, but slower clearance and higher accumulation in SKOV-3 ovarian tumor in vivo (Feng et al., 2018). Along in vitro and in vivo, ex vivo assays are also useful for studying the biocompatibility of the NBMs. Among them, the hemocompatibility can be verified by the hemolysis assay incubating them with animal or human blood samples. For instance, Janko et al utilized this assay to demonstrate that hemocompatibility can be achieved by performing a BSA corona on lauric acid-conjugated SPION (Janko et al., 2017). In vivo hematology and blood biochemistry tracking also may provide relevant information about the effects of IO NBMs in the organism. Gu et al. observed that oleic acid-coated IO NPs encapsulated in PEG-phospholipids micelles did accumulate in liver and spleen after i.v. injection $(5 \mathrm{mg} / \mathrm{kg})$ in $\mathrm{Balb} / \mathrm{c}$ mice. IO NBMs are expected to be biodegraded without toxic effects due to natural iron metabolism, but they were not completely cleared even after a month despite a significant decrease in concentration. Interestingly, the hematological studies showed that blood cell levels were in the normal range, but with increased levels of enzymes, mainly those associated to liver cells that were suggested to be related with the metabolization of oleic acid in the liver $(\mathrm{Gu}$ et al., 2012). Sangnier et al. showed that the rate of intracellular biodegradation of IO NPs by hMSC spheroid model is dependent on NBMs characteristics (Sangnier et al., 2019) such as size, morphology, and surface chemistry demonstrating their relevance on the design of biocompatible theranostic nanoagents.

Magnetic resonance image is a powerful noninvasive and nonharmful diagnostic technique that is able to provide high spatial resolution images, by monitoring the relaxation of the nuclear spin usually of protons, whose precession is synchronized by a radio frequency pulse and the intensity decay monitored as a function of time to generate 3D images (Mukhtar, et al., 2020). The so-called "nuclear spin relaxation process" takes place by two mechanisms giving rise to longitudinal $\left(T_{1}\right.$, spin-lattice) and transverse $\left(\mathrm{T}_{2}\right.$, spin-spin) relaxation times. Each compound has protons in different chemical environments, giving rise to characteristic Larmor frequencies and relaxation times, that are further influenced by the medium where they are, making it possible to generate the images. However, sometimes a contrast agent is required to improve the resolution and get more accurate information. Currently, paramagnetic gadolinium(III) chelates are generally used for such purposes in clinical practices. But it is well-known that $T_{1}$ and $T_{2}$ relaxation times are decreased by materials with magnetic properties, such as SPIONs, which can be used as contrast agents in MRI techniques (De León-Rodríguez et al., 2015). In the human body, the hydrogen atoms are present mainly in water, carbohydrates, and biomolecules. Hence, the presence or accumulation of SPIONs in certain sites/tissues (e.g. a tumor) can be used to create a much clear contrast in relation to the surrounding tissues (Mukhtar et al., 2020; Santhosh and Ulrih, 2013). There are some examples of IO-based MRI contrast nanoagents that were approved by drug regulatory 
TABLE 2 | List of marketed IO NPs based products, and their application and approval status.

\begin{tabular}{|c|c|c|c|c|c|c|}
\hline $\begin{array}{l}\text { Product name } \\
\text { and number }\end{array}$ & $\begin{array}{c}\text { Brand } \\
\text { Name(s) }\end{array}$ & $\begin{array}{c}\text { Core } \\
\text { material }\end{array}$ & Stabilizing agent & Application/Indication & Approval status & Reference \\
\hline $\begin{array}{l}\text { Ferumoxide } \\
\text { AMl-24 }\end{array}$ & $\begin{array}{l}\text { Feridex I.V. }{ }^{\circledR} \\
\text { Endorem }^{\circledR}\end{array}$ & $\mathrm{Fe}_{3} \mathrm{O}_{4}$ & Dextran & $\begin{array}{l}\text { Diagnosis: MRI contrast agent for } \\
\text { liver imaging }\end{array}$ & $\begin{array}{l}\text { Approved by FDA: } 1996 \\
\text { (Discontinued in 2008) }\end{array}$ & $\begin{array}{l}\text { Kondo et al.( 2000), } \\
\text { Senéterre et al. (1996) }\end{array}$ \\
\hline $\begin{array}{l}\text { Ferumoxsil } \\
\text { AMl-121 }\end{array}$ & $\begin{array}{l}\text { Gastromark }^{\text {TM }} \\
\text { Lumirem }^{\circledR}\end{array}$ & $\mathrm{Fe}_{3} \mathrm{O}_{4}$ & Siloxane & $\begin{array}{l}\text { Diagnosis: MRI contrast agent for } \\
\text { gastrointestinal imaging }\end{array}$ & $\begin{array}{l}\text { Approved by FDA: } 2001 \\
\text { (Discontinued in 2009) }\end{array}$ & Johnson et al. (1996) \\
\hline $\begin{array}{l}\text { Ferucarbotran } \\
\text { SHU555A }\end{array}$ & Resovist ${ }^{\circledR}$ & $\begin{array}{l}\mathrm{Fe}_{3} \mathrm{O}_{4} / \\
\mathrm{Fe}_{2} \mathrm{O}_{3}\end{array}$ & Carboxydextran & $\begin{array}{l}\text { Diagnosis: MRI contrast agent for } \\
\text { liver imaging }\end{array}$ & $\begin{array}{l}\text { Approved in some } \\
\text { European countries: } \\
2001\end{array}$ & $\begin{array}{l}\text { Sofue et al. (2010), } \\
\text { Reimer and Balzer } \\
\text { (2003) }\end{array}$ \\
\hline $\begin{array}{l}\text { Ferucarbotran } \\
\text { SHU555C }\end{array}$ & Supravist ${ }^{\circledR}$ & $\mathrm{Fe}_{3} \mathrm{O}_{4}$ & Carboxydextran & $\begin{array}{l}\text { Diagnosis: MRI contrast agent for } \\
\text { blood pooling }\end{array}$ & Clinical development & Vellinga et al. (2009) \\
\hline $\begin{array}{l}\text { Ferumoxtran-10 } \\
\text { AMl-227 }\end{array}$ & $\begin{array}{l}\text { Combidex }^{\circledR} \\
\text { Sinerem }{ }^{\circledR}\end{array}$ & $\mathrm{Fe}_{3} \mathrm{O}_{4}$ & Dextran & $\begin{array}{l}\text { Diagnosis: MRI contrast agent for } \\
\text { lymph node metastases imaging }\end{array}$ & $\begin{array}{l}\text { Application withdrawn } \\
\text { from EMA:2008 }\end{array}$ & $\begin{array}{l}\text { Heesakkers et al. } \\
\text { (2009) }\end{array}$ \\
\hline $\begin{array}{l}\text { Ferumoxytol AMl- } \\
7228\end{array}$ & $\begin{array}{l}\text { Feraheme }^{\circledR} \\
\text { Rienso }\end{array}$ & $\mathrm{Fe}_{3} \mathrm{O}_{4}$ & $\begin{array}{l}\text { Polyglucose sorbitol } \\
\text { carboxymethylether }\end{array}$ & $\begin{array}{l}\text { Therapy: Iron replacement for } \\
\text { anemia treatment in patients with } \\
\text { chronic kidney disease }\end{array}$ & Approved by FDA: 2009 & $\begin{array}{l}\text { Vasanawala et al. } \\
\text { (2016), Turkbey et al. } \\
\text { (2015) }\end{array}$ \\
\hline $\begin{array}{l}\text { Magnetic Fluid } \\
\text { MFL AS1 }\end{array}$ & NanoTherm ${ }^{\circledR}$ & $\mathrm{Fe}_{3} \mathrm{O}_{4}$ & Aminosilane & $\begin{array}{l}\text { Therapy: Hyperthermia agent for } \\
\text { glioblastoma treatment }\end{array}$ & $\begin{array}{l}\text { Approved by EMA: } \\
2010\end{array}$ & $\begin{array}{l}\text { Grauer et al. (2018), } \\
\text { Maier-Hauff et al. } \\
(2010)\end{array}$ \\
\hline
\end{tabular}

agencies, such as the United States Food and Drug Administration (FDA) and the European Medicines Agency (EMA), which are listed in Table 2 (Wang, 2011; Anselmo and Mitragotri, 2015). Interestingly, the first FDA-approved IO-based NBM was prescribed for iron replacement therapies in patients with iron deficiency (Anselmo and Mitragotri, 2015). It consisted of an iron oxide core coated with polysaccharides such as dextran and sucrose. Later on, SPIONs with similar coating layers such as ferumoxide (Feridex I.V. ${ }^{\circledR}$, Endorem ${ }^{\circledR}$ ) were approved for clinical application as MRI contrast agents. However, some of these products have been discontinued for unknown reasons. Recently, the attention has been shifted to NBMs based on ultrasmall SPIONs (USPIONs), nanoparticles with hydrodynamic diameter $<50 \mathrm{~nm}$ (Daldrup-Link, 2017). For instance, ferumoxytol $\left(\right.$ Feraheme $^{\circledR}$, Rienso ${ }^{\circledR}$ ) is a USPION originally approved for iron replacement in patients with chronic kidney disease, but that has shown potential as MRI contrast agent in clinical angiography studies due to its longer blood half-life (Daldrup-Link, 2017).

Also, considering the magnetic properties of SPIONs, we will guess, why not pulling them onto a specific location using a magnet? The magnetic concentration is possible given to the high saturation magnetization that can be achieved with SPIONs and consequent forces induced by a gradient of magnetic field thus allowing to guide and induce their accumulation in the desired site. However, the magnetic field intensity is inversely proportional to the volume and the square of the distance to the magnet does not provide a high accuracy while demanding the knowledge of the exact location of the target (Santhosh and Ulrih, 2013; Uchiyama et al., 2015). Thus, the incorporation of molecular targeting properties to NBMs is a much more attractive strategy considering the advantages associated with the selective or specific interactions, as discussed below.
In addition to the intrinsic magnetic properties explored for the development of MRI contrast agents, the rich surface coordination chemistry enables the attachment of different types of chemical species, including molecules that provide preferential interactions with specific biological structures. This possibility is rather interesting since it can be used not only to induce their accumulation in desired sites, thus decreasing the required dose for an image in diagnosis, but also to bind bioactive molecules and deliver locally the medicines in a selective way. IO NPs can be designed as passive or active vectoring antitumoral drug carriers (Santhosh and Ulrih, 2013).

The magnetic properties of IO NPs also can enable a therapy mode called magnetic hyperthermia (MHT). In this approach, an alternating magnetic field (AMF) is applied to generate enough heat to increase the local temperature and promote cell death, and/or induce the activation of the immune system. This method has a great advantage for the treatment of solid tumors since it is possible to magnetically accumulate them in the target sites, and selectively induce cancer cell death without harming the surrounding healthy tissue (Périgo et al., 2015). In 2010, EMA approved the magnetic fluid named NanoTherm ${ }^{\circledR}$ (Table 2), the first example of a product based on IO NBMs for treatment by MHT by direct injection in the tumor, followed by sessions of AMF. Clinical studies have been carried out to evaluate the effect of MHT combined with radiotherapy for the treatment of patients with glioblastoma (Maier-Hauff et al., 2010; Grauer et al., 2018). More in-depth discussion about the treatment by magnetic hyperthermia was provided by Chang et al. in a review article (Chang et al., 2018).

Many are the possibilities for designing IO nanomaterials that can rely on a single mechanism of action, as reported by Li et al. and Vyas et al., who explored IO NPs as Dox nanocarriers for treatment, respectively, of breast and liver cancer cells (Vyas et al., 
TABLE 3 | Examples of IO-based nanomaterials and its application in cancer theranostics.

\begin{tabular}{|c|c|c|c|c|c|c|c|c|}
\hline \multirow[t]{2}{*}{ Applications } & \multirow[t]{2}{*}{ Material } & \multirow{2}{*}{$\begin{array}{l}\text { Size } \\
(\mathrm{nm})\end{array}$} & \multirow[t]{2}{*}{ Shape } & \multirow[t]{2}{*}{ Stabilizing agent } & \multirow{2}{*}{$\begin{array}{l}\text { Co-adjuvant } \\
\text { agents }\end{array}$} & \multicolumn{2}{|c|}{ Biological studies } & \multirow[t]{2}{*}{ Reference } \\
\hline & & & & & & $\begin{array}{l}\text { In Vitro: Cell } \\
\text { line (cytotoxic } \\
\text { concentration) }\end{array}$ & $\begin{array}{l}\text { In Vivo: Animal } \\
\text { model (toxic } \\
\text { concentration) }\end{array}$ & \\
\hline $\begin{array}{l}\text { Chemotherapy/ } \\
\text { MHT/MRI }\end{array}$ & $\mathrm{Fe}_{3} \mathrm{O}_{4}$ & 6.9 & Sphere & Carboxymethyl cellulose & FA, Dox & $\begin{array}{l}\text { MDA-MB-23 } \\
(0.5 \mu \mathrm{g} \mathrm{NP} / \mathrm{ml}) \\
\text { HEK } 293 T \text { ( } 5.1 \mu \mathrm{g} \mathrm{NP/ml)} \\
\text { MCF-7 (C.N.E.), } \\
\text { HepG2 (C.N.E.), } \\
\text { HeLa (C.N.E.) }\end{array}$ & - & $\begin{array}{l}\text { Mansur et al. } \\
(2020)\end{array}$ \\
\hline $\begin{array}{l}\text { Chemotherapy/ } \\
\text { MRI }\end{array}$ & $\mathrm{Fe}_{3} \mathrm{O}_{4}$ & 14 & Sphere & PEG & FA, Dox & $\begin{array}{l}\text { HeLa } \\
(10 \mu g \text { Dox-NP/ml) }\end{array}$ & - & $\begin{array}{l}\text { Rajkumar and } \\
\text { Prabaharan, } \\
\text { (2018) }\end{array}$ \\
\hline $\begin{array}{l}\text { Drug } \\
\text { Delivery/MRI }\end{array}$ & $\mathrm{Fe}_{3} \mathrm{O}_{4}$ & $9-14$ & Sphere & PEG, Polyethylenimine & FA, Dox & $\begin{array}{l}\text { MCF-7 } \\
(4-6 \mu g \text { Dox-NP/ml) }\end{array}$ & $\begin{array}{l}\text { Balb/c Mice } \\
\text { (N.T. } 5 \text { mg Dox-NP/kg) }\end{array}$ & $\begin{array}{l}\text { Huang et al. } \\
(2017)\end{array}$ \\
\hline $\begin{array}{l}\text { Drug Delivery } \\
\text { /MRI/PTT }\end{array}$ & $\mathrm{Fe}_{3} \mathrm{O}_{4}$ & $200-300$ & Sphere & Polydopamine & $\begin{array}{l}\text { Dox, gold } \\
\text { nanocage, } \\
\text { MIL101- } \\
\mathrm{NH}_{2} \mathrm{MOF}\end{array}$ & 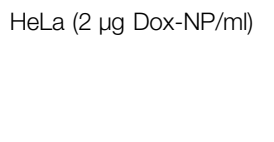 & $\begin{array}{l}\text { Balb/c Mice } \\
\text { (N.T. } 2 \text { ug Dox-NP/g) }\end{array}$ & $\begin{array}{l}\text { Li Q et al. } \\
(2021)\end{array}$ \\
\hline $\begin{array}{l}\text { Magnetic } \\
\text { Resonance } \\
\text { Imaging }\end{array}$ & $\mathrm{Fe}_{3} \mathrm{O}_{4}$ & 6.9 & Sphere & $\begin{array}{l}\text { N-phosphonomethyl } \\
\text { iminodiacetic acid }\end{array}$ & FA & - & $\begin{array}{l}\text { Wistar Rats } \\
\text { (N.T. } 10 \mathrm{mg} \mathrm{NP/kg)}\end{array}$ & $\begin{array}{l}\text { Uchiyama } \\
\text { et al. (2015) }\end{array}$ \\
\hline MHT/PTा & $\mathrm{Fe}_{3} \mathrm{O}_{4}$ & 20 & Cube & PEG-gallol & - & $\begin{array}{l}\text { KOV3 (N.C. at } 12 \mathrm{mM} \mathrm{Fe} \text { ), } \\
\text { PC3 (N.C. at } 12 \mathrm{mM} \mathrm{Fe} \text { ), } \\
\text { A43 (N.C. at } 12 \mathrm{mM} \mathrm{Fe)}\end{array}$ & NMRI mice (T.N.E.) & $\begin{array}{l}\text { Espinosa } \\
\text { et al. (2016) }\end{array}$ \\
\hline $\begin{array}{l}\text { MRI/NIRI/ } \\
\text { USI/PTT }\end{array}$ & $\mathrm{Fe}_{3} \mathrm{O}_{4}$ & 190 & Sphere & $\begin{array}{l}\text { Poly-lactide-co- } \\
\text { glycolide NPs }\end{array}$ & $\begin{array}{l}\text { Dox, IR780, } \\
\text { perfluoropentane }\end{array}$ & $\begin{array}{l}4 \mathrm{~T} 1 \\
(0.2-0.4 \mathrm{mg} \mathrm{NPs} / \mathrm{ml})\end{array}$ & Balb/c Mice (T.N.E.) & $\begin{array}{l}\text { Wang et al. } \\
\text { (2018) }\end{array}$ \\
\hline MRI/PET & $\mathrm{Fe}_{3} \mathrm{O}_{4}$ & $2.2-6.6$ & Sphere & Heparin oligosaccharides & ${ }^{68} \mathrm{Ga}$ & 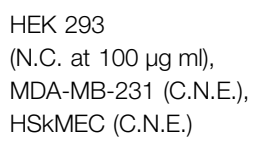 & SCID Mice (T.N.E.) & $\begin{array}{l}\text { Groult et al. } \\
(2021)\end{array}$ \\
\hline $\begin{array}{l}\text { MRI/PET MRI/ } \\
\text { SPECT }\end{array}$ & $\mathrm{Fe}_{3} \mathrm{O}_{4}$ & $8-10$ & Sphere & Phosphorylethanolamine & $\begin{array}{l}\text { DTPA, }{ }^{68} \mathrm{Ga}, \\
{ }^{99 m} \mathrm{Tc}, \\
\text { Trastuzumab }\end{array}$ & - & Balb/c Mice (T.N.E.) & $\begin{array}{l}\text { de Souza } \\
\text { Albernaz et al. } \\
\text { (2018) }\end{array}$ \\
\hline
\end{tabular}

Abbreviations: C.N.E., cytotoxicity in vitro not evaluated; Dox, doxorubicin; DTPA, diethylene triamine pentaacetic acid; FA, folic acid; MHT, magnetic hyperthermia therapy; MOF, metallorganic framework; MRI, magnetic resonance imaging; N.C., no cytotoxicity observed; NP, nanoparticle; N.T., no toxicity observed in major systemic organs; NIRI, near-infrared imaging; PEG, polyethylene glycol; PET, pósitron emission tomography; PTT, photothermal therapy; SPECT, single-photon emission computed tomography; T.N.E., in vivo toxicity was not evaluated; USI, ultrasound imaging.

2015; Li and Zhang, 2020). Nevertheless, the current trend is the development of multifunctional NBMs combining different therapies in the quest for synergistic effects, thus enhancing the efficacy of the treatment, while incorporating simultaneous image diagnostics capability (Cai et al., 2017). For instance, several groups reported the use of IO NBMs for simultaneous treatment by Dox-targeted delivery and magnetic hyperthermia, coupled with image diagnostic by MRI, thus demonstrating the potentiality and good perspectives of such types of theranostic agents (Huang et al., 2017; Angelopoulou et al., 2019; Mansur et al., 2020). Furthermore, a common feature in these works is the use of FA as targeting agent to improve their selectivity towards cancer cell lines overexpressing folate receptors. A recent work showed that the conjugation of FA on SPIONs enhanced the cellular uptake of the corresponding NBM by HeLa cells, demonstrating the possibility of active targeting to selectively favor their accumulation in tumor tissues (Deda et al., 2017; Deda et al., 2021).

The design of nanosystems based on iron oxide NBMs for controlled drug release is another promising area that is being intensively pursued using different approaches, such as drug encapsulation in the polymeric coating layer (Khaledian et al., 2020; Tsai et al., 2020), or by drug co-encapsulation in micelles (Bai et al., 2018; Manigandan et al., 2018), hydrogels (Indulekha et al., 2017; Zou et al., 2020), liposomes (Jose et al., 2019; Szuplewska et al., 2019), lipid NPs (Świętek et al., 2020), polymeric NPs (Mosafer et al., 2017; Luque-Michel et al., 2021), and mesoporous silica nanostructures (Asghar et al., 
2020). The stimulated release is a very interesting strategy since it allows a better control on the delivery, ensuring the medicine will be released in the desired site and the therapeutic dose will be achieved (Santhosh and Ulrih, 2013; Monnier et al., 2014). Another important issue that can be avoided is the burst effect, associated with a sudden increase of physiological drug concentration upon administration of NP-based formulations in living organisms. Hence, the cancer treatment efficacy will be remarkably improved by utilizing stimulus-response-based release nanosystems. For example, the release can be induced by local changes in $\mathrm{pH}$ (Bai et al., 2018) or temperature (Dorjsuren et al., 2020), or by irradiation of AMF (Fortes Brollo et al., 2020) or high-energy photons (Di Corato et al., 2015).

Another interesting strategy that has been explored in the treatment of cancer is photothermal therapy (PTT), following the current trend on new multifunctional nanosystems. In order to achieve a multimodal treatment, it is necessary to produce NBMs with synergic and/or complementary features, for example, conjugating antitumoral drugs and photosensitizers for PDT (Di Corato et al., 2015; Sun et al., 2019), or photothermal conversion agents (PTCA) such as organic dyes and gold NPs (Espinosa et al., 2015; Wang et al., 2018; Li and Zhang, 2020) for PTT. Briefly, PTT is a new cancer therapy modality that explores the photothermal property of NIR-lightabsorbing materials, such as plasmonic or semiconducting carbon nanomaterials, to generate heat and induce tumor cells death, in a similar way to magnetic hyperthermia. However, until very recently, the use of IO NPs had been limited to MHT combined with drug delivery chemotherapy, such that the PTT property of magnetite NBMs had been barely investigated. But, this has changed after Chu et al. and Shen et al. showed that enough heat is generated upon NIR irradiation of $\mathrm{Fe}_{3} \mathrm{O}_{4}$ NPs to increase the local temperature and induce cancer cells death, thus demonstrating their potential as PTCAs (Chu et al., 2013; Shen et al., 2013). In addition, Espinosa et al. and Shen et al. reported that IO-based NBMs can have photothermal efficiencies comparable to gold nanomaterials (Shen et al., 2013; Espinosa et al., 2016). Nevertheless, the property was shown to be highly dependent on aggregation state and morphology of the iron oxide nanocrystals, where the effect can be enhanced by conjugation of NIR absorbing polymers such as polydopamine (Liao et al., 2012; Shen et al., 2013; Chen et al., 2014; Espinosa et al., 2016). Since these findings, the number of works reporting on IO magnetic NPs for PTT combined with other therapy modalities has increased (Huang et al., 2015; Guo et al., 2017; Oh et al., 2017; Yang et al., 2017; Fathy et al., 2021). In fact, magnetite NBMs are being intensively studied aiming for application as multimodal cancer theranostic agents.

The works presented to demonstrate the high potential of IO NBMs for real application in cancer theranostics. Iron oxides exhibit interesting optical and magnetic properties and have a versatile surface chemistry allowing easy conjugation of molecular species, as well as fine control of their size and morphology. Such possibilities are listed in Table 3 where some examples of NBMs and their related applications are presented, as well as the conjugated stabilizing and co- adjuvant agents employed, and the in vitro or in vivo model utilized in the biological assays.

\section{PERSPECTIVES AND CONCLUSION}

Health problems caused by diseases and tumors are among the many problems faced by our society, where cancer probably is one of the most pernicious and complex, thus demanding innovative solutions. In all cases, early diagnostics and treatment probably are the most recommended protocol, especially if based on personalized materials that seek and concentrate on specific targets dispersed in the body. Such kind of technology can become a reality but depends on the development of innovative smart nanobiomaterials able to overcome the harsh conditions imposed by the biological environment, such as the clearance and immune system, which rapidly can filtrate them out from the vascular system. These processes make them unavailable imposing the need of much larger concentrations to achieve the therapeutic dose and proportionally larger risk of unwanted side effects. Accordingly, stealthing strategies such as the conjugation of zwitterionic species, extracellular vesicle, or cell membranes, or even the use of properly treated cells, such as emptied RBCs, as shuttles, are being proposed to improve the circulation time. However, targeting is a fundamental property that must be implemented in all, even in such more sophisticated NBMs, to make then smarter and safer, while fulfilling requirements of CS, size, and morphology, as well as of a functional load of diagnostic and/or therapeutic agents. Clearly, this is a description of multiconjugated multi-functional nanomachines where iron oxide and titanium dioxide nanoparticles are two highly biocompatible materials that can be used as platform. They encompass high surface areas and structural stability, exhibit mild and flexible enough surface chemistry as well as useful magnetic, optical, and semiconducting properties that can be explored in diagnostic by resonance magnetic image, treatment by hyperthermia, and local generation of very reactive species, respectively. However, it is highly recommended to include in the development protocol, careful systematic studies in media mimicking as close as possible the biological fluids and biological environments of in vivo systems since tests carried out in water tend to provide misleading results. For instance, CS is a fundamental property that tends to be highly influenced by the medium in which the NBMs are dispersed, such that the agglomeration or aggregation can completely change the uptake, pharmacokinetics, biolocalization, and clearance. Accordingly, the formation of a corona should also be carefully evaluated, but it can be controlled by adjusting the surface chemistry or used to improve the colloidal stability and circulation time taking benefit of the stealthing properties it can impart. In short, this review summarized the current understanding and state of the art on the design of smart nanobiomaterials based on $\mathrm{IO}$ and $\mathrm{TiO}_{2}$ nanoparticles as platform. In fact, innovative nanomaterials for application in personalized molecular diagnostics and therapy of diseases can be realized by multi-functionalization and coconjugation of complimentary molecular species opening great new perspectives in the biomedical area. 


\section{AUTHOR CONTRIBUTIONS}

RKK contributed to the general design, conceptualization, and preparation of the manuscript, the figures, and tables; MR contributed to the revision and the preparation of the figures and tables; ND contributed to the search and construction of the tables; KA contributed to the conceptualization, supervision, and final revision of the work. All authors contributed to the writing, reviewed, and gave the final approval to the manuscript.

\section{FUNDING}

This work was supported by Conselho Nacional de Desenvolvimento Científico e Tecnológico (CNPq grants no. 401581/2016-0, 303137/2016-9 and 442599/2019-6), Fundação de Amparo à Pesquisa do Estado de São Paulo (FAPESP grants

\section{REFERENCES}

Abdel-Ghany, S., Raslan, S., Tombuloglu, H., Shamseddin, A., Cevik, E., Said, O. A., et al. (2020). Vorinostat-loaded Titanium Oxide Nanoparticles (Anatase) Induce G2/M Cell Cycle Arrest in Breast Cancer Cells via PALB2 Upregulation. 3 Biotech. 10, 407. doi:10.1007/S13205-020-02391-2

Abdollah, M. R. A., Carter, T. J., Jones, C., Kalber, T. L., Rajkumar, V., Tolner, B., et al. (2018). Fucoidan Prolongs the Circulation Time of Dextran-Coated Iron Oxide Nanoparticles. ACS Nano 12, 1156-1169. doi:10.1021/ ACSNANO.7B06734

Abou Hassan, A., Sandre, O., Cabuil, V., and Tabeling, P. (2008). Synthesis of Iron Oxide Nanoparticles in a Microfluidic Device: Preliminary Results in a Coaxial Flow Millichannel. Chem. Commun. 2008, 1783-1785. doi:10.1039/B719550H

Albanese, A., and Chan, W. C. W. (2011). Effect of Gold Nanoparticle Aggregation on Cell Uptake and Toxicity. ACS Nano 5, 5478-5489. doi:10.1021/NN2007496

Alemán, J. V., Chadwick, A. V., He, J., Hess, M., Horie, K., Jones, R. G., et al. (2007). Definitions of Terms Relating to the Structure and Processing of Sols, Gels, Networks, and Inorganic-Organic Hybrid Materials (IUPAC Recommendations 2007). Pure Appl. Chem. 79, 1801-1829. doi:10.1351/ PAC200779101801

Alkilany, A. M., Mahmoud, N. N., Hashemi, F., Hajipour, M. J., Farvadi, F., and Mahmoudi, M. (2016). Misinterpretation in Nanotoxicology: A Personal Perspective. Chem. Res. Toxicol. 29, 943-948. doi:10.1021/ ACS.CHEMRESTOX.6B00108

Angelopoulou, A., Kolokithas-Ntoukas, A., Fytas, C., and Avgoustakis, K. (2019). Folic Acid-Functionalized, Condensed Magnetic Nanoparticles for Targeted Delivery of Doxorubicin to Tumor Cancer Cells Overexpressing the Folate Receptor. ACS Omega 4, 22214-22227. doi:10.1021/ACSOMEGA.9B03594

Anselmo, A. C., Gupta, V., Zern, B. J., Pan, D., Zakrewsky, M., Muzykantov, V., et al. (2013). Delivering Nanoparticles to Lungs while Avoiding Liver and Spleen through Adsorption on Red Blood Cells. ACS Nano 7, 11129-11137. doi:10.1021/NN404853Z

Anselmo, A. C., and Mitragotri, S. (2015). A Review of Clinical Translation of Inorganic Nanoparticles. AAPS J. 17, 1041-1054. doi:10.1208/S12248-0159780-2

Anselmo, A. C., and Mitragotri, S. (2014). Cell-mediated Delivery of Nanoparticles: Taking Advantage of Circulatory Cells to Target Nanoparticles. J. Controlled Release 190, 531-541. doi:10.1016/J.JCONREL.2014.03.050

Antoniou, C., Kosmadaki, M., Stratigos, A., and Katsambas, A. (2008). Sunscreens What's Important to Know. J. Eur. Acad. Dermatol. Venereol. 22, 1110-1119. doi:10.1111/J.1468-3083.2007.02580.X

Apolinário, A. C., Hirata, A. S., Anjos Miguel, R. D., Costa-Lotufo, L. V., Pessoa, A., La Clair, J. J., et al. (2020). Exploring the Benefits of Nanotechnology for Cancer Drugs in Different Stages of the Drug Development Pipeline. Nanomedicine 15, 2539-2542. doi:10.2217/NNM-2020-0290 no. 2018/21489-1, 2019/02151-2), and Coordenação de Aperfeiçoamento de Pessoal de Nível Superior (CAPES grant no. 88881.465527/2019-01, and program 33002010191PO).

\section{ACKNOWLEDGMENTS}

The authors gratefully acknowledge the financial support by Conselho National de Desenvolvimento Científico e Tecnológico (CNPq), Fundação de Amparo à Pesquisa do Estado de São Paulo (FAPESP) and Coordenação de Aperfeiçoamento de Pessoal de Nível Superior (CAPES). Doctoral fellowships from FAPESP (grant no. 2019/02151-2 to RKK) and CAPES (program 33002010191PO to MR and ND) are greatly appreciated. KA acknowledge the financial support by CNPq (401581/2016-0, 303137/2016-9, and 442599/2019-6), FAPESP (2018/21489-1) and (CAPES 88881.465527/2019-01).

Araki, K., Uchiyama, M., Toma, S., Rodrigues, S., Shimada, A., Loiola, R., et al. (2015). Ultrasmall Cationic Superparamagnetic Iron Oxide Nanoparticles as Nontoxic and Efficient MRI Contrast Agent and Magnetic-Targeting Tool. Int. J. Nanomedicine 10, 4731-4746. doi:10.2147/IJN.S83150

Arteaga-Cardona, F., Gutiérrez-García, E., Hidalgo-Tobón, S., López-Vasquez, C., Brito-Barrera, Y. A., Flores-Tochihuitl, J., et al. (2016). Cell Viability and MRI Performance of Highly Efficient Polyol-Coated Magnetic Nanoparticles. J. Nanopart Res. 18, 345. doi:10.1007/S11051-016-3646-0

Asghar, K., Qasim, M., Dharmapuri, G., and Das, D. (2020). Thermoresponsive Polymer Gated and Superparamagnetic Nanoparticle Embedded Hollow Mesoporous Silica Nanoparticles as Smart Multifunctional Nanocarrier for Targeted and Controlled Delivery of Doxorubicin. Nanotechnology 31, 455604. doi:10.1088/1361-6528/AB8B0E

Ashby, J., Pan, S., and Zhong, W. (2014). Size and Surface Functionalization of Iron Oxide Nanoparticles Influence the Composition and Dynamic Nature of Their Protein Corona. ACS Appl. Mater. Inter. 6, 15412-15419. doi:10.1021/ AM503909Q

Augustin, E., Czubek, B., Nowicka, A. M., Kowalczyk, A., Stojek, Z., and Mazerska, Z. (2016). Improved Cytotoxicity and Preserved Level of Cell Death Induced in colon Cancer Cells by Doxorubicin after its Conjugation with Iron-Oxide Magnetic Nanoparticles. Toxicol. Vitro 33, 45-53. doi:10.1016/ J.TIV.2016.02.009

Aula, S., Lakkireddy, S., Jamil, K., Kapley, A., Swamy, A. V. N., and Lakkireddy, H. R. (2015). Biophysical, Biopharmaceutical and Toxicological Significance of Biomedical Nanoparticles. RSC Adv. 5, 47830-47859. doi:10.1039/ C5RA05889A

Babes, L., Denizot, B., Tanguy, G., Le Jeune, J. J., and Jallet, P. (1999). Synthesis of Iron Oxide Nanoparticles Used as MRI Contrast Agents: A Parametric Study. J. Colloid Interf. Sci. 212, 474-482. doi:10.1006/JCIS.1998.6053

Bachler, G., von Goetz, N., and Hungerbuhler, K. (2015). Using Physiologically Based Pharmacokinetic (PBPK) Modeling for Dietary Risk Assessment of Titanium Dioxide (TiO2) Nanoparticles. Nanotoxicology 9, 373-380. doi:10.3109/17435390.2014.940404

Bai, M.-Y., Tang, S.-L., Chuang, M.-H., Wang, T.-Y., and Hong, P.-d. (2018). Evaluation of Chitosan Derivative Microparticles Encapsulating Superparamagnetic Iron Oxide and Doxorubicin as a pH-Sensitive Delivery Carrier in Hepatic Carcinoma Treatment: An In Vitro Comparison Study. Front. Pharmacol. 9, 1025. doi:10.3389/FPHAR.2018.01025

Bai, S., Yang, N., Wang, X., Gong, F., Dong, Z., Gong, Y., et al. (2020). Ultrasmall Iron-Doped Titanium Oxide Nanodots for Enhanced Sonodynamic and Chemodynamic Cancer Therapy. ACS Nano 14, 15119-15130. doi:10.1021/ ACSNANO.0C05235

Behnam, M. A., Emami, F., Sobhani, Z., and Dehghanian, A. R. (2018). The Application of Titanium Dioxide (TiO2) Nanoparticles in the Photo-thermal Therapy of Melanoma Cancer Model. Iran. J. Basic Med. Sci. 21, 1133-1139. doi:10.22038/IJBMS.2018.30284.7304 
Boverhof, D. R., Bramante, C. M., Butala, J. H., Clancy, S. F., Lafranconi, M., West, J., et al. (2015). Comparative Assessment of Nanomaterial Definitions and Safety Evaluation Considerations. Regul. Toxicol. Pharmacol. 73, 137-150. doi:10.1016/J.YRTPH.2015.06.001

Brenner, J. S., Pan, D. C., Myerson, J. W., Marcos-Contreras, O. A., Villa, C. H., Patel, P., et al. (2018). Red Blood Cell-Hitchhiking Boosts Delivery of Nanocarriers to Chosen Organs by Orders of Magnitude. Nat. Commun. 9, 2684. doi:10.1038/s41467-018-05079-7

Cai, P., Leow, W. R., Wang, X., Wu, Y.-L., and Chen, X. (2017). Programmable Nano-Bio Interfaces for Functional Biointegrated Devices. Adv. Mater. 29, 1605529. doi:10.1002/ADMA.201605529

Cai, R., Ren, J., Ji, Y., Wang, Y., Liu, Y., Chen, Z., et al. (2020). Corona of Thorns: The Surface Chemistry-Mediated Protein Corona Perturbs the Recognition and Immune Response of Macrophages. ACS Appl. Mater. Inter. 12, 1997-2008. doi:10.1021/ACSAMI.9B15910

Carney, R. P., Kim, J. Y., Qian, H., Jin, R., Mehenni, H., Stellacci, F., et al. (2011). Determination of Nanoparticle Size Distribution Together with Density or Molecular Weight by 2D Analytical Ultracentrifugation. Nat. Commun. 2, 335. doi:10.1038/ncomms1338

Carrillo-Carrion, C., Carril, M., and Parak, W. J. (2017). Techniques for the Experimental Investigation of the Protein corona. Curr. Opin. Biotechnol. 46, 106-113. doi:10.1016/J.COPBIO.2017.02.009

Cędrowska, E., Pruszynski, M., Majkowska-Pilip, A., Męczyńska-Wielgosz, S., Bruchertseifer, F., Morgenstern, A., et al. (2018). Functionalized TiO2 Nanoparticles Labelled with 225Ac for Targeted Alpha Radionuclide Therapy. J. Nanopart Res. 20, 83. doi:10.1007/S11051-018-4181-Y

Chambers, E., and Mitragotri, S. (2004). Prolonged Circulation of Large Polymeric Nanoparticles by Non-covalent Adsorption on Erythrocytes. J. Controlled Release 100, 111-119. doi:10.1016/J.JCONREL.2004.08.005

Champion, J. A., and Mitragotri, S. (2006). Role of Target Geometry in Phagocytosis. Proc. Natl. Acad. Sci. 103, 4930-4934. doi:10.1073/ PNAS.0600997103

Chang, D., Lim, M., Goos, J. A. C. M., Qiao, R., Ng, Y. Y., Mansfeld, F. M., et al. (2018). Biologically Targeted Magnetic Hyperthermia: Potential and Limitations. Front. Pharmacol. 9, 831. doi:10.3389/FPHAR.2018.00831

Chen, H., Burnett, J., Zhang, F., Zhang, J., Paholak, H., and Sun, D. (2014). Highly Crystallized Iron Oxide Nanoparticles as Effective and Biodegradable Mediators for Photothermal Cancer Therapy. J. Mater. Chem. B 2, 757-765. doi:10.1039/С3ТВ21338B

Chen, Y., Lin, H., Tong, R., An, N., and Qu, F. (2017). Near-infrared LightMediated DOX-UCNPs@mHTiO2 Nanocomposite for Chemo/photodynamic Therapy and Imaging. Colloids Surf. B: Biointerfaces 154, 429-437. doi:10.1016/ J.COLSURFB.2017.03.026

Cho, W.-S., Duffin, R., Bradley, M., Megson, I. L., MacNee, W., Lee, J. K., et al. (2013). Predictive Value of In Vitro Assays Depends on the Mechanism of Toxicity of Metal Oxide Nanoparticles. Part. Fibre Toxicol. 10, 55. doi:10.1186/ 1743-8977-10-55

Chouhan, R. S., Horvat, M., Ahmed, J., Alhokbany, N., Alshehri, S. M., and Gandhi, S. (2021). Magnetic Nanoparticles-A Multifunctional Potential Agent for Diagnosis and Therapy. Cancers 13, 2213. doi:10.3390/CANCERS13092213

Chu, M., Shao, Y., Peng, J., Dai, X., Li, H., Wu, Q., et al. (2013). Near-infrared Laser Light Mediated Cancer Therapy by Photothermal Effect of Fe3O4 Magnetic Nanoparticles. Biomaterials 34, 4078-4088. doi:10.1016/ J.BIOMATERIALS.2013.01.086

Clogston, J. D., and Patri, A. K. (2011). "Zeta Potential Measurement," in Characterization of Nanoparticles Intended for Drug Delivery. Editor S. E. McNeil (New York: Humana Press), 63-70. doi:10.1007/978-1-60327-198-1_6

Corbo, C., Molinaro, R., Parodi, A., Toledano Furman, N. E., Salvatore, F., and Tasciotti, E. (2016). The Impact of Nanoparticle Protein corona on Cytotoxicity, Immunotoxicity and Target Drug Delivery. Nanomedicine 11, 81-100. doi:10.2217/NNM.15.188

Corbo, C., Molinaro, R., Tabatabaei, M., Farokhzad, O. C., and Mahmoudi, M. (2017). Personalized Protein corona on Nanoparticles and its Clinical Implications. Biomater. Sci. 5, 378-387. doi:10.1039/C6BM00921B

Cree, I. A., and Charlton, P. (2017). Molecular Chess? Hallmarks of Anti-cancer Drug Resistance. BMC Cancer 17, 10. doi:10.1186/S12885-016-2999-1

Dadfar, S. M., Roemhild, K., Drude, N. I., von Stillfried, S., Knüchel, R., Kiessling, F., et al. (2019). Iron Oxide Nanoparticles: Diagnostic, Therapeutic and
Theranostic Applications. Adv. Drug Deliv. Rev. 138, 302-325. doi:10.1016/ J.ADDR.2019.01.005

Daldrup-Link, H. E. (2017). Ten Things You Might Not Know about Iron Oxide Nanoparticles. Radiology 284, 616-629. doi:10.1148/RADIOL.2017162759

De León-Rodríguez, L. M., Martins, A. F., Pinho, M. C., Rofsky, N. M., and Sherry, A. D. (2015). Basic MR Relaxation Mechanisms and Contrast Agent Design. J. Magn. Reson. Imaging 42, 545-565. doi:10.1002/JMRI.24787

de Souza Albernaz, M., Toma, S. H., Clanton, J., Araki, K., and Santos-Oliveira, R. (2018). Decorated Superparamagnetic Iron Oxide Nanoparticles with Monoclonal Antibody and Diethylene-Triamine-Pentaacetic Acid Labeled with Thechnetium-99m and Galium-68 for Breast Cancer Imaging. Pharm. Res. 35, 24. doi:10.1007/S11095-017-2320-2

Deda, D. K., Cardoso, R. M., Kawassaki, R. K., de Oliveira, A. R., Toma, S. H., Baptista, M. S., et al. (2021). Cytotoxicity of Methotrexate Conjugated to Glycerol Phosphate Modified Superparamagnetic Iron Oxide Nanoparticles. J. Nanosci. Nanotechnol. 21, 1451-1461. doi:10.1166/JNN.2021.19027

Deda, D. K., Cardoso, R. M., Uchiyama, M. K., Pavani, C., Toma, S. H., Baptista, M. S., et al. (2017). A Reliable Protocol for Colorimetric Determination of Iron Oxide Nanoparticle Uptake by Cells. Anal. Bioanal. Chem. 409, 6663-6675. doi:10.1007/S00216-017-0622-1

Deda, D. K., Iglesias, B. A., Alves, E., Araki, K., and Garcia, C. R. S. (2020). Porphyrin Derivative Nanoformulations for Therapy and Antiparasitic Agents. Molecules 25, 2080. doi:10.3390/MOLECULES25092080

Dhavale, R. P., Dhavale, R. P., Sahoo, S. C., Kollu, P., Jadhav, S. U., Patil, P. S., et al. (2021). Chitosan Coated Magnetic Nanoparticles as Carriers of Anticancer Drug Telmisartan: $\mathrm{pH}$-Responsive Controlled Drug Release and Cytotoxicity Studies. J. Phys. Chem. Sol. 148, 109749. doi:10.1016/J.JPCS.2020.109749

Di Corato, R., Béalle, G., Kolosnjaj-Tabi, J., Espinosa, A., Clément, O., Silva, A. K. A., et al. (2015). Combining Magnetic Hyperthermia and Photodynamic Therapy for Tumor Ablation with Photoresponsive Magnetic Liposomes. ACS Nano 9, 2904-2916. doi:10.1021/NN506949T

Dolores, R., Raquel, S., and Adianez, G.-L. (2015). Sonochemical Synthesis of Iron Oxide Nanoparticles Loaded with Folate and Cisplatin: Effect of Ultrasonic Frequency. Ultrason. Sonochem. 23, 391-398. doi:10.1016/ J.ULTSONCH.2014.08.005

Donahue, N. D., Acar, H., and Wilhelm, S. (2019). Concepts of Nanoparticle Cellular Uptake, Intracellular Trafficking, and Kinetics in Nanomedicine. $A d v$. Drug Deliv. Rev. 143, 68-96. doi:10.1016/J.ADDR.2019.04.008

Dorjsuren, B., Chaurasiya, B., Ye, Z., Liu, Y., Li, W., Wang, C., et al. (2020). Cetuximab-Coated Thermo-Sensitive Liposomes Loaded with Magnetic Nanoparticles and Doxorubicin for Targeted EGFR-Expressing Breast Cancer Combined Therapy. Int. J. Nanomedicine 15, 8201-8215. doi:10.2147/IJN.S261671

dos Santos, A. l. F., de Almeida, D. R. Q., Terra, L. F., Baptista, M. c. S., and Labriola, L. (2019). Photodynamic Therapy in Cancer Treatment - an Update Review. J. Cancer Metastasis Treat. 2019, 25. doi:10.20517/2394-4722.2018.83

Dréno, B., Alexis, A., Chuberre, B., and Marinovich, M. (2019). Safety of Titanium Dioxide Nanoparticles in Cosmetics. J. Eur. Acad. Dermatol. Venereol. 33, 34-46. doi:10.1111/JDV.15943

Du, Y., Ren, W., Li, Y., Zhang, Q., Zeng, L., Chi, C., et al. (2015). The Enhanced Chemotherapeutic Effects of Doxorubicin Loaded PEG Coated $\mathrm{TiO} 2$ Nanocarriers in an Orthotopic Breast Tumor Bearing Mouse Model. J. Mater. Chem. B 3, 1518-1528. doi:10.1039/C4TB01781A

Edwards, S. A., and Williams, D. R. M. (2004). Double Layers and Interparticle Forces in Colloid Science and Biology: Analytic Results for the Effect of Ionic Dispersion Forces. Phys. Rev. Lett. 92, 248303. doi:10.1103/ PhysRevLett. 92.248303

Elbasuney, S. (2017). Sustainable Steric Stabilization of Colloidal Titania Nanoparticles. Appl. Surf. Sci. 409, 438-447. doi:10.1016/ J.APSUSC.2017.03.013

Elgrabli, D., Beaudouin, R., Jbilou, N., Floriani, M., Pery, A., Rogerieux, F., et al. (2015). Biodistribution and Clearance of $\mathrm{TiO} 2$ Nanoparticles in Rats after Intravenous Injection. PLoS One 10, e0124490. doi:10.1371/ JOURNAL.PONE.0124490

Escoda-Torroella, M., Moya, C., Rodríguez, A. F., Batlle, X., and Labarta, A. (2021). Selective Control over the Morphology and the Oxidation State of Iron Oxide Nanoparticles. Langmuir 37, 35-45. doi:10.1021/ ACS.LANGMUIR.0C02221 
Espinosa, A., Bugnet, M., Radtke, G., Neveu, S., Botton, G. A., Wilhelm, C., et al. (2015). Can Magneto-Plasmonic Nanohybrids Efficiently Combine Photothermia with Magnetic Hyperthermia? Nanoscale 7, 18872-18877. doi:10.1039/C5NR06168G

Espinosa, A., Di Corato, R., Kolosnjaj-Tabi, J., Flaud, P., Pellegrino, T., and Wilhelm, C. (2016). Duality of Iron Oxide Nanoparticles in Cancer Therapy: Amplification of Heating Efficiency by Magnetic Hyperthermia and Photothermal Bimodal Treatment. ACS Nano 10, 2436-2446. doi:10.1021/ACSNANO.5B07249

Fabian, E., Landsiedel, R., Ma-Hock, L., Wiench, K., Wohlleben, W., and van Ravenzwaay, B. (2008). Tissue Distribution and Toxicity of Intravenously Administered Titanium Dioxide Nanoparticles in Rats. Arch. Toxicol. 82, 151-157. doi:10.1007/S00204-007-0253-Y

Fang, R. H., Kroll, A. V., Gao, W., and Zhang, L. (2018). Cell Membrane Coating Nanotechnology. Adv. Mater. 30, 1706759. doi:10.1002/ ADMA.201706759

Fathy, M. M., Nasser, L., El-Sokkary, G., and Rasheedy, M. S. (2021). Combined Chemo-Photothermal Therapy of Metastatic Mammary Adenocarcinoma Using Curcumin-Coated Iron Oxide Nanoparticles. BioNanoSci. 11, 447-453. doi:10.1007/S12668-021-00841-6

Fazilati, M. (2014). Anti-neoplastic Applications of Heparin Coated Magnetic Nanoparticles against Human Ovarian Cancer. J. Inorg. Organomet. Polym. 24, 551-559. doi:10.1007/S10904-013-0005-9

Feng, Q., Liu, Y., Huang, J., Chen, K., Huang, J., and Xiao, K. (2018). Uptake, Distribution, Clearance, and Toxicity of Iron Oxide Nanoparticles with Different Sizes and Coatings. Sci. Rep. 8, 2082. doi:10.1038/s41598-01819628-z

Feng, X., Zhai, J., and Jiang, L. (2005). The Fabrication and Switchable Superhydrophobicity of $\mathrm{TiO} 2$ Nanorod Films. Angew. Chem. Int. Ed. 44, 5115-5118. doi:10.1002/ANIE.200501337

Fernández, M., Javaid, F., and Chudasama, V. (2018). Advances in Targeting the Folate Receptor in the Treatment/imaging of Cancers. Chem. Sci. 9, 790-810. doi:10.1039/C7SC04004K

Ferretti, A. M., Usseglio, S., Mondini, S., Drago, C., La Mattina, R., Chini, B., et al. (2021). Towards Bio-Compatible Magnetic Nanoparticles: Immune-Related Effects, In-Vitro Internalization, and In-Vivo Bio-Distribution of Zwitterionic Ferrite Nanoparticles with Unexpected Renal Clearance. J. Colloid Interf. Sci. 582, 678-700. doi:10.1016/J.JCIS.2020.08.026

Flak, D., Yate, L., Nowaczyk, G., and Jurga, S. (2017). Hybrid ZnPc@TiO 2 Nanostructures for Targeted Photodynamic Therapy, Bioimaging and Doxorubicin Delivery. Mater. Sci. Eng. C 78, 1072-1085. doi:10.1016/ J.MSEC.2017.04.107

Fortes Brollo, M. E., Domínguez-Bajo, A., Tabero, A., Domínguez-Arca, V., Gisbert, V., Prieto, G., et al. (2020). Combined Magnetoliposome Formation and Drug Loading in One Step for Efficient Alternating Current-Magnetic Field Remote-Controlled Drug Release. ACS Appl. Mater. Inter. 12, 4295-4307. doi:10.1021/ACSAMI.9B20603

Francia, V., Yang, K., Deville, S., Reker-Smit, C., Nelissen, I., and Salvati, A. (2019). Corona Composition Can Affect the Mechanisms Cells Use to Internalize Nanoparticles. ACS Nano 13, 11107-11121. doi:10.1021/ACSNANO.9B03824

Geraets, L., Oomen, A. G., Krystek, P., Jacobsen, N. R., Wallin, H., Laurentie, M., et al. (2014). Tissue Distribution and Elimination after Oral and Intravenous Administration of Different Titanium Dioxide Nanoparticles in Rats. Part. Fibre Toxicol. 11, 30. doi:10.1186/1743-8977-11-30

Grauer, O., Jaber, M., Hess, K., Weckesser, M., Schwindt, W., Maring, S., et al. (2018). Combined Intracavitary Thermotherapy with Iron Oxide Nanoparticles and Radiotherapy as Local Treatment Modality in Recurrent Glioblastoma Patients. J. Neurooncol. 141, 83-94. doi:10.1007/S11060-018-03005-X

Grenier, P., Viana, I. M. D. O., Lima, E. M., and Bertrand, N. (2018). Antipolyethylene Glycol Antibodies Alter the Protein corona Deposited on Nanoparticles and the Physiological Pathways Regulating Their Fate In Vivo. J. Controlled Release 287, 121-131. doi:10.1016/J.JCONREL.2018.08.022

Groult, H., Carregal-Romero, S., Castejón, D., Azkargorta, M., Miguel-Coello, A.B., Pulagam, K. R., et al. (2021). Heparin Length in the Coating of Extremely Small Iron Oxide Nanoparticles Regulates In Vivo Theranostic Applications. Nanoscale 13, 842-861. doi:10.1039/D0NR06378A

Groult, H., Poupard, N., Herranz, F., Conforto, E., Bridiau, N., Sannier, F., et al. (2017). Family of Bioactive Heparin-Coated Iron Oxide Nanoparticles with Positive Contrast in Magnetic Resonance Imaging for Specific Biomedical
Applications. Biomacromolecules 18, 3156-3167. doi:10.1021/ ACS.BIOMAC.7B00797

Gu, F. X., Karnik, R., Wang, A. Z., Alexis, F., Levy-Nissenbaum, E., Hong, S., et al. (2007). Targeted Nanoparticles for Cancer Therapy. Nano Today 2, 14-21. doi:10.1016/S1748-0132(07)70083-X

Gu, L., Fang, R. H., Sailor, M. J., and Park, J.-H. (2012). In Vivo Clearance and Toxicity of Monodisperse Iron Oxide Nanocrystals. ACS Nano 6, 4947-4954. doi:10.1021/NN300456Z

Guardia, P., Pérez, N., Labarta, A., and Batlle, X. (2010). Controlled Synthesis of Iron Oxide Nanoparticles over a Wide Size Range. Langmuir 26, 5843-5847. doi:10.1021/LA903767E

Guibert, C., Dupuis, V., Peyre, V., and Fresnais, J. (2015). Hyperthermia of Magnetic Nanoparticles: Experimental Study of the Role of Aggregation. J. Phys. Chem. C 119, 28148-28154. doi:10.1021/ACS.JPCC.5B07796

Gulati, N. M., Stewart, P. L., and Steinmetz, N. F. (2018). Bioinspired Shielding Strategies for Nanoparticle Drug Delivery Applications. Mol. Pharmaceutics 15, 2900-2909. doi:10.1021/ACS.MOLPHARMACEUT.8B00292

Guo, X., Li, W., Luo, L., Wang, Z., Li, Q., Kong, F., et al. (2017). External Magnetic Field-Enhanced Chemo-Photothermal Combination Tumor Therapy via Iron Oxide Nanoparticles. ACS Appl. Mater. Inter. 9, 16581-16593. doi:10.1021/ ACSAMI.6B16513

Gyergyek, S., Makovec, D., Jagodič, M., Drofenik, M., Schenk, K., Jordan, O., et al. (2017). Hydrothermal Growth of Iron Oxide NPs with a Uniform Size Distribution for Magnetically Induced Hyperthermia: Structural, Colloidal and Magnetic Properties. J. Alloys Compd. 694, 261-271. doi:10.1016/ J.JALLCOM.2016.09.238

Hanahan, D., and Weinberg, R. A. (2011). Hallmarks of Cancer: The Next Generation. Cell 144, 646-674. doi:10.1016/J.CELL.2011.02.013

Heesakkers, R. A. M., Jager, G. J., Hövels, A. M., de Hoop, B., van den Bosch, H. C. M., Raat, F., et al. (2009). Prostate Cancer: Detection of Lymph Node Metastases outside the Routine Surgical Area with Ferumoxtran-10-Enhanced MR Imaging. Radiology 251, 408-414. doi:10.1148/RADIOL.2512071018

Hoek, E. M. V., and Agarwal, G. K. (2006). Extended DLVO Interactions between Spherical Particles and Rough Surfaces. J. Colloid Interf. Sci. 298, 50-58. doi:10.1016/J.JCIS.2005.12.031

Hong, H., Zhang, Y., Sun, J., and Cai, W. (2009). Molecular Imaging and Therapy of Cancer with Radiolabeled Nanoparticles. Nano Today 4, 399-413. doi:10.1016/J.NANTOD.2009.07.001

Hotze, E. M., Phenrat, T., and Lowry, G. V. (2010). Nanoparticle Aggregation: Challenges to Understanding Transport and Reactivity in the Environment. J. Environ. Qual. 39, 1909-1924. doi:10.2134/JEQ2009.0462

Huang, C.-C., Chang, P.-Y., Liu, C.-L., Xu, J.-P., Wu, S.-P., and Kuo, W.-C. (2015). New Insight on Optical and Magnetic Fe3O4 Nanoclusters Promising for Near Infrared Theranostic Applications. Nanoscale 7, 12689-12697. doi:10.1039/ C5NR03157E

Huang, Y., Mao, K., Zhang, B., and Zhao, Y. (2017). Superparamagnetic Iron Oxide Nanoparticles Conjugated with Folic Acid for Dual Target-specific Drug Delivery and MRI in Cancer Theranostics. Mater. Sci. Eng. C 70, 763-771. doi:10.1016/J.MSEC.2016.09.052

Indulekha, S., Arunkumar, P., Bahadur, D., and Srivastava, R. (2017). Dual Responsive Magnetic Composite Nanogels for Thermo-Chemotherapy. Colloids Surf. B: Biointerfaces 155, 304-313. doi:10.1016/ J.COLSURFB.2017.04.035

International Organization for Standardization (2015). ISO/TS 80004-2:2015(en) Nanotechnologies - Vocabulary - Part 2: Nano-objects. Geneva: International Organization for Standardization.

Jana, B., Mondal, G., Biswas, A., Chakraborty, I., and Ghosh, S. (2013). Functionalised $\mathrm{TiO} 2$ Nanoparticles Deliver Oligo-Histidine and Avidin Tagged Biomolecules Simultaneously into the Cell. RSC Adv. 3, 8215-8219. doi:10.1039/C3RA41068D

Janer, G., Mas del Molino, E., Fernández-Rosas, E., Fernández, A., and VázquezCampos, S. (2014). Cell Uptake and Oral Absorption of Titanium Dioxide Nanoparticles. Toxicol. Lett. 228, 103-110. doi:10.1016/J.TOXLET.2014.04.014

Jang, B., Kwon, H., Katila, P., Lee, S. J., and Lee, H. (2016). Dual Delivery of Biological Therapeutics for Multimodal and Synergistic Cancer Therapies. Adv. Drug Deliv. Rev. 98, 113-133. doi:10.1016/J.ADDR.2015.10.023

Janko, C., Zaloga, J., Pöttler, M., Dürr, S., Eberbeck, D., Tietze, R., et al. (2017). Strategies to Optimize the Biocompatibility of Iron Oxide Nanoparticles - 
"SPIONs Safe by Design". J. Magnetism Magn. Mater. 431, 281-284. doi:10.1016/J.JMMM.2016.09.034

Jeon, M., Lin, G., Stephen, Z. R., Kato, F. L., and Zhang, M. (2019). PaclitaxelLoaded Iron Oxide Nanoparticles for Targeted Breast Cancer Therapy. Adv. Therap. 2, 1900081. doi:10.1002/ADTP.201900081

Jiang, W. F., Ling, Y. H., Hao, S. J., Li, H. Y., Bai, X. D., and Cang, D. Q. (2007). In Situ Template Synthesis of TiO2 Nanotube Array Films. Key Eng. Mater. 336-338, 2200-2202. doi:10.4028/www.scientific.net/kem.336-338.2200

Joh, D. Y., Zimmers, Z., Avlani, M., Heggestad, J. T., Aydin, H. B., Ganson, N., et al. (2019). Architectural Modification of Conformal PEG-Bottlebrush Coatings Minimizes Anti-PEG Antigenicity while Preserving Stealth Properties. Adv. Healthc. Mater. 8, 1801177. doi:10.1002/ADHM.201801177

Johnson, W. K., Stoupis, C., Torres, G. M., Rosenberg, E. B., and Ros, P. R. (1996). Superparamagnetic Iron Oxide (SPIO) as an Oral Contrast Agent in Gastrointestinal (GI) Magnetic Resonance Imaging (MRI): Comparison with State-Of-The-Art Computed Tomography (CT). Magn. Reson. Imaging 14, 43-49. doi:10.1016/0730-725X(95)02044-T

Jose, G., Lu, Y.-J., Chen, H.-A., Hsu, H.-L., Hung, J.-T., Anilkumar, T. S., et al. (2019). Hyaluronic Acid Modified Bubble-Generating Magnetic Liposomes for Targeted Delivery of Doxorubicin. J. Magnetism Magn. Mater. 474, 355-364. doi:10.1016/J.JMMM.2018.11.019

Kafshgari, M. K., Kah, D., Mazare, A., Nguyen, N. T., Distaso, M., Peukert, W., et al. (2019). Anodic Titanium Dioxide Nanotubes for Magnetically Guided Therapeutic Delivery. Sci. Rep. 9, 13439. doi:10.1038/s41598-019-49513-2

Kamps, K., Leek, R., Luebke, L., Price, R., Nelson, M., Simonet, S., et al. (2013). Surface Modification of the TiO2 nanoparticle Surface Enables Fluorescence Monitoring of Aggregation and Enhanced Photoreactivity. Integr. Biol. 5, 133-143. doi:10.1039/C2IB20166F

Khaledian, M., Nourbakhsh, M. S., Saber, R., Hashemzadeh, H., and Darvishi, M. H. (2020). Preparation and Evaluation of Doxorubicin-Loaded PLA-PEG-FA Copolymer Containing Superparamagnetic Iron Oxide Nanoparticles (SPIONs) for Cancer Treatment: Combination Therapy with Hyperthermia and Chemotherapy. Int. J. Nanomedicine 15, 6167-6182. doi:10.2147/ IJN.S261638

Kim, C.-S., Moon, B. K., Park, J.-H., Choi, B.-C., and Seo, H.-J. (2003). Solvothermal Synthesis of Nanocrystalline $\mathrm{TiO} 2$ in Toluene with Surfactant. J. Cryst. Growth 257, 309-315. doi:10.1016/S0022-0248(03)01468-4

Kim, S., Im, S., Park, E.-Y., Lee, J., Kim, C., Kim, T.-i., et al. (2020). Drug-loaded Titanium Dioxide Nanoparticle Coated with Tumor Targeting Polymer as a Sonodynamic Chemotherapeutic Agent for Anti-cancer Therapy. Nanomedicine: Nanotechnology, Biol. Med. 24, 102110. doi:10.1016/ J.NANO.2019.102110

Kondo, H., Kanematsu, M., Hoshi, H., Murakami, T., Kim, T., Hori, M., et al. (2000). Preoperative Detection of Malignant Hepatic Tumors. Am. J. Roentgenology 174, 947-954. doi:10.2214/AJR.174.4.1740947

Kou, J., Dou, D., Yang, L., Kou, J., Dou, D., and Yang, L. (2017). Porphyrin Photosensitizers in Photodynamic Therapy and its Applications. Oncotarget 8, 81591-81603. doi:10.18632/ONCOTARGET.20189

LaGrow, A. P., Besenhard, M. O., Hodzic, A., Sergides, A., Bogart, L. K., Gavriilidis, A., et al. (2019). Unravelling the Growth Mechanism of the Co-precipitation of Iron Oxide Nanoparticles with the Aid of Synchrotron X-Ray Diffraction in Solution. Nanoscale 11, 6620-6628. doi:10.1039/C9NR00531E

Lai, Y.-K., Wang, Q., Huang, J.-Y., Li, H.-Q., Chen, Z., Zhao, A. Z.-J., et al. (2016). $\mathrm{TiO}_{2}$ Nanotube Platforms for Smart Drug Delivery: a Review. Int. J. Nanomedicine 11, 4819-4834. doi:10.2147/IJN.S108847

Lamb, J., and Holland, J. P. (2018). Advanced Methods for Radiolabeling Multimodality Nanomedicines for SPECT/MRI and PET/MRI. J. Nucl. Med. 59, 382-389. doi:10.2967/JNUMED.116.187419

Lane, D. D., Black, K. C. L., Raliya, R., Reed, N., Kotagiri, N., Gilson, R., et al. (2020). Effects of Core Titanium crystal Dimension and crystal Phase on ROS Generation and Tumour Accumulation of Transferrin Coated Titanium Dioxide Nanoaggregates. RSC Adv. 10, 23759-23766. doi:10.1039/ D0RA01878C

Laurent, S., Forge, D., Port, M., Roch, A., Robic, C., Vander Elst, L., et al. (2008). Magnetic Iron Oxide Nanoparticles: Synthesis, Stabilization, Vectorization, Physicochemical Characterizations, and Biological Applications. Chem. Rev. 108, 2064-2110. doi:10.1021/CR068445E
Lemine, O. M., Omri, K., Iglesias, M., Velasco, V., Crespo, P., De La Presa, P., et al. (2014). $\gamma$-Fe2O3 by Sol-Gel with Large Nanoparticles Size for Magnetic Hyperthermia Application. J. Alloys Compd. 607, 125-131. doi:10.1016/ J.JALLCOM.2014.04.002

Li, J., Li, L., Lv, Y., Zou, H., Wei, Y., Nie, F., et al. (2020). The Construction of the Novel Magnetic Prodrug Fe3O4@DOX and its Antagonistic Effects on Hepatocarcinoma with Low Toxicity. RSC Adv. 10, 28965-28974. doi:10.1039/D0RA01729A

Li, Q., Lin, B., Li, Y., and Lu, N. (2021). Erythrocyte-Camouflaged Mesoporous Titanium Dioxide Nanoplatform for an Ultrasound-Mediated Sequential Therapies of Breast Cancer. Int. J. Nanomedicine 16, 3875-3887. doi:10.2147/IJN.S301855

Li, Q., Wang, X., Lu, X., Tian, H., Jiang, H., Lv, G., et al. (2009). The Incorporation of Daunorubicin in Cancer Cells through the Use of Titanium Dioxide Whiskers. Biomaterials 30, 4708-4715. doi:10.1016/ J.BIOMATERIALS.2009.05.015

Li, S., Shi, X., Wang, H., and Xiao, L. (2021). A Multifunctional Dual-shell Magnetic Nanocomposite with Near-infrared Light Response for Synergistic Chemo-thermal Tumor Therapy. J. Biomed. Mater. Res. 109, 841-852. doi:10.1002/JBM.B.34749

Li, S., and Zhang, L. (2020). Erythrocyte Membrane Nano-Capsules: Biomimetic Delivery and Controlled Release of Photothermal-Photochemical Coupling Agents for Cancer Cell Therapy. Dalton Trans. 49, 2645-2651. doi:10.1039/ C9DT04335G

Liao, M.-Y., Lai, P.-S., Yu, H.-P., Lin, H.-P., and Huang, C.-C. (2012). Innovative Ligand-Assisted Synthesis of NIR-Activated Iron Oxide for Cancer Theranostics. Chem. Commun. 48, 5319-5321. doi:10.1039/C2CC31448G

Liu, X., Chen, H.-j., Chen, X., Alfadhl, Y., Yu, J., and Wen, D. (2015). Radiofrequency Heating of Nanomaterials for Cancer Treatment: Progress, Controversies, and Future Development. Appl. Phys. Rev. 2, 011103. doi:10.1063/1.4915002

Luque-Michel, E., Lemaire, L., and Blanco-Prieto, M. J. (2021). SPION and Doxorubicin-Loaded Polymeric Nanocarriers for Glioblastoma Theranostics. Drug Deliv. Transl. Res. 11, 515-523. doi:10.1007/S13346-020-00880-8

Ma, D., Chen, J., Luo, Y., Wang, H., and Shi, X. (2017). Zwitterion-coated Ultrasmall Iron Oxide Nanoparticles for Enhanced T1-Weighted Magnetic Resonance Imaging Applications. J. Mater. Chem. B 5, 7267-7273. doi:10.1039/ C7TB01588G

Ma, S.-N., Mao, Z.-X., Wu, Y., Liang, M.-X., Wang, D.-D., Chen, X., et al. (2020). The Anti-cancer Properties of Heparin and its Derivatives: a Review and prospect. Cell Adhes. Migration 14, 118-128. doi:10.1080/ 19336918.2020.1767489

Maier-Hauff, K., Ulrich, F., Nestler, D., Niehoff, H., Wust, P., Thiesen, B., et al. (2010). Efficacy and Safety of Intratumoral Thermotherapy Using Magnetic Iron-Oxide Nanoparticles Combined with External Beam Radiotherapy on Patients with Recurrent Glioblastoma Multiforme. J. Neurooncol. 103, 317-324. doi:10.1007/S11060-010-0389-0

Manigandan, A., Handi, V., Sundaramoorthy, N. S., Dhandapani, R., Radhakrishnan, J., Sethuraman, S., et al. (2018). Responsive Nanomicellar Theranostic Cages for Metastatic Breast Cancer. Bioconjug. Chem. 29, 275-286. doi:10.1021/ACS.BIOCONJCHEM.7B00577

Mansur, A. A. P., Mansur, H. S., Leonel, A. G., Carvalho, I. C., Lage, M. C. G., Carvalho, S. M., et al. (2020). Supramolecular Magnetonanohybrids for Multimodal Targeted Therapy of Triple-Negative Breast Cancer Cells. J. Mater. Chem. B 8, 7166-7188. doi:10.1039/D0TB01175D

Martínez-Mera, I., Espinosa-Pesqueira, M. E., Pérez-Hernández, R., and ArenasAlatorre, J. (2007). Synthesis of Magnetite (Fe3O4) Nanoparticles without Surfactants at Room Temperature. Mater. Lett. 61, 4447-4451. doi:10.1016/ J.MATLET.2007.02.018

McNamara, K., and Tofail, S. A. M. (2017). Nanoparticles in Biomedical Applications. Adv. Phys. X 2, 54-88. doi:10.1080/23746149.2016.1254570

Melo, F. M. D., Mattioni, J. V., Dias, F., Fu, Y., and Toma, H. E. (2021). Solvophobic-controlled Synthesis of Smart Magneto-Fluorescent Nanostructures for Real-Time Inspection of Metallic Fractures. Nanoscale Adv. 3, 3593-3604. doi:10.1039/D1NA00149C

Mishra, M., and Chun, D.-M. (2015). $\alpha-\mathrm{Fe} 2 \mathrm{O} 3$ as a Photocatalytic Material: A Review. Appl. Catal. A: Gen. 498, 126-141. doi:10.1016/J.APCATA.2015.03.023 
Mo, S., Shao, X., Chen, Y., and Cheng, Z. (2016). Increasing Entropy for Colloidal Stabilization. Sci. Rep. 6, 36836. doi:10.1038/srep36836

Mohammadalipour, Z., Rahmati, M., Khataee, A., and Moosavi, M. A. (2020). Differential Effects of N-TiO2 Nanoparticle and its Photo-activated Form on Autophagy and Necroptosis in Human Melanoma A375 Cells. J. Cel. Physiol. 235, 8246-8259. doi:10.1002/JCP.29479

Mondini, S., Leonzino, M., Drago, C., Ferretti, A. M., Usseglio, S., Maggioni, D., et al. (2015). Zwitterion-Coated Iron Oxide Nanoparticles: Surface Chemistry and Intracellular Uptake by Hepatocarcinoma (HepG2) Cells. Langmuir 31, 7381-7390. doi:10.1021/ACS.LANGMUIR.5B01496

Monnier, C. A., Burnand, D., Rothen-Rutishauser, B., Lattuada, M., and Petri-Fink, A. (2014). Magnetoliposomes: Opportunities and Challenges. Eur. J. Nanomedicine 6, 201-215. doi:10.1515/EJNM-2014-0042

Moore, T. L., Rodriguez-Lorenzo, L., Hirsch, V., Balog, S., Urban, D., Jud, C., et al. (2015). Nanoparticle Colloidal Stability in Cell Culture media and Impact on Cellular Interactions. Chem. Soc. Rev. 44, 6287-6305. doi:10.1039/C4CS00487F

Morita, K., Nishimura, Y., Nakamura, S., Arai, Y., Numako, C., Sato, K., et al. (2021). Titanium Oxide Nano-Radiosensitizers for Hydrogen Peroxide Delivery into Cancer Cells. Colloids Surf. B: Biointerfaces 198, 111451. doi:10.1016/J.COLSURFB.2020.111451

Mosafer, J., Abnous, K., Tafaghodi, M., Mokhtarzadeh, A., and Ramezani, M. (2017). In Vitro and In Vivo Evaluation of Anti-nucleolin-targeted Magnetic PLGA Nanoparticles Loaded with Doxorubicin as a Theranostic Agent for Enhanced Targeted Cancer Imaging and Therapy. Eur. J. Pharmaceutics Biopharmaceutics 113, 60-74. doi:10.1016/J.EJPB.2016.12.009

Moya, C., Escudero, R., Malaspina, D. C., de la Mata, M., Hernández-Saz, J., Faraudo, J., et al. (2019). Insights into Preformed Human Serum Albumin Corona on Iron Oxide Nanoparticles: Structure, Effect of Particle Size, Impact on MRI Efficiency, and Metabolization. ACS Appl. Bio Mater. 2, 3084-3094. doi:10.1021/ACSABM.9B00386

Mukhtar, A., Wu, K., Cao, X., and Gu, 1. (2020). Magnetic Nanowires in Biomedical Applications. Nanotechnology 31, 433001. doi:10.1088/13616528/ABA1BA

Nel, A. E., Mädler, L., Velegol, D., Xia, T., Hoek, E. M. V., Somasundaran, P., et al. (2009). Understanding Biophysicochemical Interactions at the Nano-Bio Interface. Nat. Mater 8, 543-557. doi:10.1038/nmat2442

Nosrati, H., Sefidi, N., Sharafi, A., Danafar, H., and Kheiri Manjili, H. (2018). Bovine Serum Albumin (BSA) Coated Iron Oxide Magnetic Nanoparticles as Biocompatible Carriers for Curcumin-Anticancer Drug. Bioorg. Chem. 76, 501-509. doi:10.1016/J.BIOORG.2017.12.033

Nyongesa, F., and Aduda, B. (2017). Electrophoretic Deposition of Titanium Dioxide Thin Films for Photocatalytic Water Purification Systems. Adv. Mater. 6, 31. doi:10.11648/J.AM.20170604.11

Oh, S.-M., and Ishigaki, T. (2004). Preparation of Pure Rutile and Anatase TiO2 Nanopowders Using RF thermal Plasma. Thin Solid Films 457, 186-191. doi:10.1016/J.TSF.2003.12.043

Oh, Y., Je, J.-Y., Moorthy, M. S., Seo, H., and Cho, W. H. (2017). pH and NIRLight-Responsive Magnetic Iron Oxide Nanoparticles for MitochondriaMediated Apoptotic Cell Death Induced by Chemo-Photothermal Therapy. Int. J. Pharmaceutics 531, 1-13. doi:10.1016/J.IJPHARM.2017.07.014

Okuya, M., Shiozaki, K., Horikawa, N., Kosugi, T., Kumara, G. R. A., Madarász, J., et al. (2004). Porous TiO2 Thin Films Prepared by spray Pyrolysis Deposition (SPD) Technique and Their Application to UV Sensors. Solid State Ionics 172, 527-531. doi:10.1016/J.SSI.2004.02.060

Oskam, G., Nellore, A., Penn, R. L., and Searson, P. C. (2003). The Growth Kinetics of TiO2Nanoparticles from Titanium(IV) Alkoxide at High Water/Titanium Ratio. J. Phys. Chem. B 107, 1734-1738. doi:10.1021/JP021237F

Papini, E., Tavano, R., and Mancin, F. (2020). Opsonins and Dysopsonins of Nanoparticles: Facts, Concepts, and Methodological Guidelines. Front. Immunol. 11, 567365. doi:10.3389/FIMMU.2020.567365

Périgo, E. A., Hemery, G., Sandre, O., Ortega, D., Garaio, E., Plazaola, F., et al. (2015). Fundamentals and Advances in Magnetic Hyperthermia. Appl. Phys. Rev. 2, 041302. doi:10.1063/1.4935688

Piffoux, M., Nicolás-Boluda, A., Mulens-Arias, V., Richard, S., Rahmi, G., Gazeau, F., et al. (2019). Extracellular Vesicles for Personalized Medicine: The Input of Physically Triggered Production, Loading and Theranostic Properties. Adv. Drug Deliv. Rev. 138, 247-258. doi:10.1016/J.ADDR.2018.12.009
Pinals, R. L., Chio, L., Ledesma, F., and Landry, M. P. (2020). Engineering at the Nano-Bio Interface: Harnessing the Protein corona towards Nanoparticle Design and Function. Analyst 145, 5090-5112. doi:10.1039/D0AN00633E

Plan Sangnier, A., Van de Walle, A. B., Curcio, A., Le Borgne, R., Motte, L., Lalatonne, Y., et al. (2019). Impact of Magnetic Nanoparticle Surface Coating on Their Long-Term Intracellular Biodegradation in Stem Cells. Nanoscale 11, 16488-16498. doi:10.1039/C9NR05624F

Prodan, A. M., Iconaru, S. L., Ciobanu, C. S., Chifiriuc, M. C., Stoicea, M., and Predoi, D. (2013). Iron Oxide Magnetic Nanoparticles: Characterization and Toxicity Evaluation byIn VitroandIn VivoAssays. J. Nanomater. 2013, 1-10. doi:10.1155/2013/587021

Qi, Y., Simakova, A., Ganson, N. J., Li, X., Luginbuhl, K. M., Ozer, I., et al. (2017). A brush-polymer/exendin-4 Conjugate Reduces Blood Glucose Levels for up to Five Days and Eliminates Poly(ethylene Glycol) Antigenicity. Nat. Biomed. Eng. 1, 0002. doi:10.1038/s41551-016-0002

Raja, G., Cao, S., Kim, D.-H., and Kim, T.-J. (2020). Mechanoregulation of Titanium Dioxide Nanoparticles in Cancer Therapy. Mater. Sci. Eng. C 107, 110303. doi:10.1016/J.MSEC.2019.110303

Rajkumar, S., and Prabaharan, M. (2018). Multi-functional Nanocarriers Based on Iron Oxide Nanoparticles Conjugated with Doxorubicin, Poly(ethylene Glycol) and Folic Acid as Theranostics for Cancer Therapy. Colloids Surf. B: Biointerfaces 170, 529-537. doi:10.1016/J.COLSURFB.2018.06.051

Rao, L., Bu, L.-L., Xu, J.-H., Cai, B., Yu, G.-T., Yu, X., et al. (2015). Red Blood Cell Membrane as a Biomimetic Nanocoating for Prolonged Circulation Time and Reduced Accelerated Blood Clearance. Small 11, 6225-6236. doi:10.1002/ SMLL.201502388

Rao, L., Cai, B., Bu, L.-L., Liao, Q.-Q., Guo, S.-S., Zhao, X.-Z., et al. (2017). Microfluidic Electroporation-Facilitated Synthesis of Erythrocyte MembraneCoated Magnetic Nanoparticles for Enhanced Imaging-Guided Cancer Therapy. ACS Nano 11, 3496-3505. doi:10.1021/ACSNANO.7B00133

Reimer, P., and Balzer, T. (2003). Ferucarbotran (Resovist): a New Clinically Approved RES-specific Contrast Agent for Contrast-Enhanced MRI of the Liver: Properties, Clinical Development, and Applications. Eur. Radiol. 13, 1266-1276. doi:10.1007/S00330-002-1721-7

Ren, X., Zheng, R., Fang, X., Wang, X., Zhang, X., Yang, W., et al. (2016). Red Blood Cell Membrane Camouflaged Magnetic Nanoclusters for Imaging-Guided Photothermal Therapy. Biomaterials 92, 13-24. doi:10.1016/ J.BIOMATERIALS.2016.03.026

Ritz, S., Schöttler, S., Kotman, N., Baier, G., Musyanovych, A., Kuharev, J., et al. (2015). Protein Corona of Nanoparticles: Distinct Proteins Regulate the Cellular Uptake. Biomacromolecules 16, 1311-1321. doi:10.1021/ ACS.BIOMAC.5B00108

Roca, A. G., Gutiérrez, L., Gavilán, H., Fortes Brollo, M. E., VeintemillasVerdaguer, S., and Morales, M. D. P. (2019). Design Strategies for ShapeControlled Magnetic Iron Oxide Nanoparticles. Adv. Drug Deliv. Rev. 138, 68-104. doi:10.1016/J.ADDR.2018.12.008

Romano, M., Uchiyama, M. K., Cardoso, R. M., Toma, S. H., Baptista, M. S., and Araki, K. (2020). Nitric Oxide Inhibition of Lipopolysaccharide-Stimulated RAW 247.6 Cells by Ibuprofen-Conjugated Iron Oxide Nanoparticles. Nanomedicine 15, 2475-2492. doi:10.2217/NNM-2020-0214

Řehoř, I., Vili'mova', V., Jendelova', P., Kubi'ček, V., Jira'k, D., Herynek, V., et al. (2011). Phosphonate-Titanium Dioxide Assemblies: Platform for Multimodal Diagnostic-Therapeutic Nanoprobes. J. Med. Chem. 54, 5185-5194. doi:10.1021/JM200449Y

Safi, M., Courtois, J., Seigneuret, M., Conjeaud, H., and Berret, J.-F. (2011). The Effects of Aggregation and Protein corona on the Cellular Internalization of Iron Oxide Nanoparticles. Biomaterials 32, 9353-9363. doi:10.1016/ J.BIOMATERIALS.2011.08.048

Salvati, A., Pitek, A. S., Monopoli, M. P., Prapainop, K., Bombelli, F. B., Hristov, D. R., et al. (2013). Transferrin-functionalized Nanoparticles Lose Their Targeting Capabilities when a Biomolecule corona Adsorbs on the Surface. Nat. Nanotech 8, 137-143. doi:10.1038/nnano.2012.237

Santhosh, P. B., and Ulrih, N. P. (2013). Multifunctional Superparamagnetic Iron Oxide Nanoparticles: Promising Tools in Cancer Theranostics. Cancer Lett. 336, 8-17. doi:10.1016/J.CANLET.2013.04.032

Santi, M., Maccari, G., Mereghetti, P., Voliani, V., Rocchiccioli, S., Ucciferri, N., et al. (2017). Rational Design of a Transferrin-Binding Peptide Sequence 
Tailored to Targeted Nanoparticle Internalization. Bioconjug. Chem. 28, 471-480. doi:10.1021/ACS.BIOCONJCHEM.6B00611

Schlenoff, J. B. (2014). Zwitteration: Coating Surfaces with Zwitterionic Functionality to Reduce Nonspecific Adsorption. Langmuir 30, 9625-9636. doi:10.1021/LA500057J

Schöttler, S., Becker, G., Winzen, S., Steinbach, T., Mohr, K., Landfester, K., et al. (2016). Protein Adsorption Is Required for Stealth Effect of Poly(ethylene Glycol)- and Poly(phosphoester)-Coated Nanocarriers. Nat. Nanotech 11, 372-377. doi:10.1038/nnano.2015.330

Seifried, S., Winterer, M., and Hahn, H. (2000). Nanocrystalline Titania Films and Particles by Chemical Vapor Synthesis. Chem. Vap. Deposition 6, 239-244. doi:10.1002/1521-3862(200010)6:5<239::aid-cvde239>3.0.co;2-q

Senéterre, E., Taourel, P., Bouvier, Y., Pradel, J., Van Beers, B., Daures, J. P., et al. (1996). Detection of Hepatic Metastases: Ferumoxides-Enhanced MR Imaging versus Unenhanced MR Imaging and CT during Arterial Portography. Radiology 200, 785-792. doi:10.1148/RADIOLOGY.200.3.8756932

Sepand, M. R., Ghavami, M., Zanganeh, S., Stacks, S., Ghasemi, F., Montazeri, H., et al. (2020). Impact of Plasma Concentration of Transferrin on Targeting Capacity of Nanoparticles. Nanoscale 12, 4935-4944. doi:10.1039/ C9NR08784B

Sette, A., Spadavecchia, J., Landoulsi, J., Casale, S., Haye, B., Crociani, O., et al. (2013). Development of Novel Anti-kv 11.1 Antibody-Conjugated PEG-TiO2 Nanoparticles for Targeting Pancreatic Ductal Adenocarcinoma Cells. J. Nanopart Res. 15, 2111. doi:10.1007/S11051-013-2111-6

Shen, S., Kong, F., Guo, X., Wu, L., Shen, H., Xie, M., et al. (2013). CMCTS Stabilized Fe3O4 Particles with Extremely Low Toxicity as Highly Efficient Near-Infrared Photothermal Agents for In Vivo Tumor Ablation. Nanoscale 5, 8056-8066. doi:10.1039/C3NR01447A

Shi, Z., Zhang, K., Zada, S., Zhang, C., Meng, X., Yang, Z., et al. (2020). Upconversion Nanoparticle-Induced Multimode Photodynamic Therapy Based on a Metal-Organic Framework/Titanium Dioxide Nanocomposite. ACS Appl. Mater. Inter. 12, 12600-12608. doi:10.1021/ACSAMI.0C01467

Silva, A. K. A., Kolosnjaj-Tabi, J., Bonneau, S., Marangon, I., Boggetto, N., Aubertin, K., et al. (2013). Magnetic and Photoresponsive Theranosomes: Translating Cell-Released Vesicles into Smart Nanovectors for Cancer Therapy. ACS Nano 7, 4954-4966. doi:10.1021/NN400269X

Singh, D., Dilnawaz, F., and Sahoo, S. K. (2020). Challenges of Moving Theranostic Nanomedicine into the Clinic. Nanomedicine 15, 111-114. doi:10.2217/NNM2019-0401

Singh, N., Marets, C., Boudon, J., Millot, N., Saviot, L., and Maurizi, L. (2021). In Vivo protein corona on Nanoparticles: Does the Control of All Material Parameters orient the Biological Behavior? Nanoscale Adv. 3, 1209-1229. doi:10.1039/D0NA00863J

Sjögren, C. E., Johansson, C., Nævestad, A., Sontum, P. C., Briley-Sæbø, K., and Fahlvik, A. K. (1997). Crystal Size and Properties of Superparamagnetic Iron Oxide (SPIO) Particles. Magn. Reson. Imaging 15, 55-67. doi:10.1016/S0730725X(96)00335-9

Soenen, S. J., Parak, W. J., Rejman, J., and Manshian, B. (2015). (Intra)Cellular Stability of Inorganic Nanoparticles: Effects on Cytotoxicity, Particle Functionality, and Biomedical Applications. Chem. Rev. 115, 2109-2135. doi:10.1021/CR400714J

Sofue, K., Tsurusaki, M., Miyake, M., Sakurada, A., Arai, Y., and Sugimura, K. (2010). Detection of Hepatic Metastases by Superparamagnetic Iron OxideEnhanced MR Imaging: Prospective Comparison between 1.5-T and 3.0-T Images in the Same Patients. Eur. Radiol. 20, 2265-2273. doi:10.1007/S00330010-1798-3

Sousa de Almeida, M., Susnik, E., Drasler, B., Taladriz-Blanco, P., Petri-Fink, A., and Rothen-Rutishauser, B. (2021). Understanding Nanoparticle Endocytosis to Improve Targeting Strategies in Nanomedicine. Chem. Soc. Rev. 50, 5397-5434. doi:10.1039/D0CS01127D

Stark, W. J. (2011). Nanoparticles in Biological Systems. Angew. Chem. Int. Ed. 50, 1242-1258. doi:10.1002/ANIE.200906684

Stone, V., Johnston, H., and Schins, R. P. F. (2009). Development Ofin Vitrosystems for Nanotoxicology: Methodological Considerations. Crit. Rev. Toxicol. 39, 613-626. doi:10.1080/10408440903120975

Strable, E., Bulte, J. W. M., Moskowitz, B., Vivekanandan, K., Allen, M., and Douglas, T. (2001). Synthesis and Characterization of Soluble Iron
Oxide-Dendrimer Composites. Chem. Mater. 13, 2201-2209. doi:10.1021/ CM010125I

Striolo, A., and Egorov, S. A. (2007). Steric Stabilization of Spherical Colloidal Particles: Implicit and Explicit Solvent. J. Chem. Phys. 126, 014902. doi:10.1063/ 1.2409710

Sun, Q., He, F., Bi, H., Wang, Z., Sun, C., Li, C., et al. (2019). An Intelligent Nanoplatform for Simultaneously Controlled Chemo-, Photothermal, and Photodynamic Therapies Mediated by a Single NIR Light. Chem. Eng. J. 362, 679-691. doi:10.1016/J.CEJ.2019.01.095

Svenson, S. (2013). Theranostics: Are We There yet? Mol. Pharmaceutics 10, 848-856. doi:10.1021/MP300644N

Świętek, M., Panchuk, R., Skorokhyd, N., Černoch, P., Finiuk, N., Klyuchivska, O., et al. (2020). Magnetic Temperature-Sensitive Solid-Lipid Particles for Targeting and Killing Tumor Cells. Front. Chem. 8, 205. doi:10.3389/ FCHEM.2020.00205

Szekeres, M., Tóth, I. Y., Turcu, R., and Tombácz, E. (2017). The Effect of Polycarboxylate Shell of Magnetite Nanoparticles on Protein corona Formation in Blood Plasma. J. Magnetism Magn. Mater. 427, 95-99. doi:10.1016/J.JMMM.2016.11.017

Szuplewska, A., Rękorajska, A., Pocztańska, E., Krysiński, P., Dybko, A., and Chudy, M. (2019). Magnetic Field-Assisted Selective Delivery of Doxorubicin to Cancer Cells Using Magnetoliposomes as Drug Nanocarriers. Nanotechnology 30, 315101. doi:10.1088/1361-6528/AB19D3

Tacar, O., Sriamornsak, P., and Dass, C. R. (2012). Doxorubicin: an Update on Anticancer Molecular Action, Toxicity and Novel Drug Delivery Systems. J. Pharm. Pharmacol. 65, 157-170. doi:10.1111/J.2042-7158.2012.01567.X

Tegafaw, T., Xu, W., Lee, S. H., Chae, K. S., Chang, Y., and Lee, G. H. (2017). Production of Nearly Monodisperse Fe3O4 and Fe@Fe3O4 Nanoparticles in Aqueous Medium and Their Surface Modification for Biomedical Applications. Int. J. Mod. Phys. B 31, 1750014. doi:10.1142/S021797921750014X

Teja, A. S., and Koh, P.-Y. (2009). Synthesis, Properties, and Applications of Magnetic Iron Oxide Nanoparticles. Prog. Cryst. Growth Characterization Mater. 55, 22-45. doi:10.1016/J.PCRYSGROW.2008.08.003

Ternent, L., Mayoh, D. A., Lees, M. R., and Davies, G.-L. (2016). Heparin-stabilised Iron Oxide for MR Applications: a Relaxometric Study. J. Mater. Chem. B 4, 3065-3074. doi:10.1039/C6TB00832A

Thevenot, P., Cho, J., Wavhal, D., Timmons, R. B., and Tang, L. (2008). Surface Chemistry Influences Cancer Killing Effect of $\mathrm{TiO} 2$ Nanoparticles. Nanomedicine: Nanotechnology, Biol. Med. 4, 226-236. doi:10.1016/ J.NANO.2008.04.001

Tong, R., Lin, H., Chen, Y., An, N., Wang, G., Pan, X., et al. (2017). Near-infrared Mediated Chemo/photodynamic Synergistic Therapy with DOX-UCNPs@ mSiO2 /TiO2 -TC Nanocomposite. Mater. Sci. Eng. C 78, 998-1005. doi:10.1016/J.MSEC.2017.04.112

Torres Martin de Rosales, R., Tavaré, R., Glaria, A., Varma, G., Protti, A., and Blower, P. J. (2011). 99mTc-Bisphosphonate-Iron Oxide Nanoparticle Conjugates for Dual-Modality Biomedical Imaging. Bioconjug. Chem. 22, 455-465. doi:10.1021/BC100483K

Tsai, M.-F., Lo, Y.-L., Huang, Y.-C., Yu, C.-C., Wu, Y.-T., Su, C.-H., et al. (2020). Multi-Stimuli-Responsive DOX Released from Magnetosome for Tumor Synergistic Theranostics. Int. J. Nanomedicine 15, 8623-8639. doi:10.2147/ IJN.S275655

Tsoi, K. M., MacParland, S. A., Ma, X.-Z., Spetzler, V. N., Echeverri, J., Ouyang, B. et al. (2016). Mechanism of Hard-Nanomaterial Clearance by the Liver. Nat. Mater 15, 1212-1221. doi:10.1038/nmat4718

Turkbey, B., Agarwal, H. K., Shih, J., Bernardo, M., McKinney, Y. L., Daar, D., et al. (2015). A Phase I Dosing Study of Ferumoxytol for MR Lymphography at $3 \mathrm{~T}$ in Patients with Prostate Cancer. Am. J. Roentgenology 205, 64-69. doi:10.2214/ AJR.14.13009

Usuda, J., Tsutsui, H., Honda, H., Ichinose, S., Ishizumi, T., Hirata, T., et al. (2007). Photodynamic Therapy for Lung Cancers Based on Novel Photodynamic Diagnosis Using Talaporfin Sodium (NPe6) and Autofluorescence Bronchoscopy. Lung Cancer 58, 317-323. doi:10.1016/ J.LUNGCAN.2007.06.026

Vasanawala, S. S., Nguyen, K.-L., Hope, M. D., Bridges, M. D., Hope, T. A., Reeder, S. B., et al. (2016). Safety and Technique of Ferumoxytol Administration for MRI. Magn. Reson. Med. 75, 2107-2111. doi:10.1002/MRM.26151 
Veeranarayanan, S., Poulose, A. C., Mohamed, M. S., Nagaoka, Y., Iwai, S., Nakagame, Y., et al. (2012). Synthesis and Application of Luminescent Single CdS Quantum Dot Encapsulated Silica Nanoparticles Directed for Precision Optical Bioimaging. Int. J. Nanomedicine 7, 3769-3786. doi:10.2147/IJN.S31310

Vellinga, M. M., Vrenken, H., Hulst, H. E., Polman, C. H., Uitdehaag, B. M. J., Pouwels, P. J. W., et al. (2009). Use of Ultrasmall Superparamagnetic Particles of Iron Oxide (USPIO)-enhanced MRI to Demonstrate Diffuse Inflammation in the normal-appearing white Matter (NAWM) of Multiple Sclerosis (MS) Patients: An Exploratory Study. J. Magn. Reson. Imaging 29, 774-779. doi:10.1002/JMRI.21678

Villa, C. H., Anselmo, A. C., Mitragotri, S., and Muzykantov, V. (2016). Red Blood Cells: Supercarriers for Drugs, Biologicals, and Nanoparticles and Inspiration for Advanced Delivery Systems. Adv. Drug Deliv. Rev. 106, 88-103. doi:10.1016/ J.ADDR.2016.02.007

Vyas, D., Lopez-Hisijos, N., Gandhi, S., El-Dakdouki, M., Basson, M. D., Walsh, M. F., et al. (2015). Doxorubicin-hyaluronan Conjugated Super-paramagnetic Iron Oxide Nanoparticles (DOX-HA-SPION) Enhanced Cytoplasmic Uptake of Doxorubicin and Modulated Apoptosis, IL-6 Release and NF-kappaB Activity in Human MDA-MB-231 Breast Cancer Cells. J. Nanosci. Nanotechnol. 15, 6413-6422. doi:10.1166/JNN.2015.10834

Walker, S., Busatto, S., Pham, A., Tian, M., Suh, A., Carson, K., et al. (2019). Extracellular Vesicle-Based Drug Delivery Systems for Cancer Treatment. Theranostics 9, 8001-8017. doi:10.7150/THNO.37097

Wang, C., Tao, H., Cheng, L., and Liu, Z. (2011). Near-infrared Light Induced In Vivo Photodynamic Therapy of Cancer Based on Upconversion Nanoparticles. Biomaterials 32, 6145-6154. doi:10.1016/J.BIOMATERIALS.2011.05.007

Wang, L., Chen, S., Zhu, Y., Zhang, M., Tang, S., Li, J., et al. (2018). Triple-Modal Imaging-Guided Chemo-Photothermal Synergistic Therapy for Breast Cancer with Magnetically Targeted Phase-Shifted Nanoparticles. ACS Appl. Mater. Inter. 10, 42102-42114. doi:10.1021/ACSAMI.8B16323

Wang, Y., Wang, Q., and Zhang, C. (2019). Synthesis of Diamond-Shaped Mesoporous Titania Nanobricks as pH-Responsive Drug Delivery Vehicles for Cancer Therapy. ChemistrySelect 4, 8225-8228. doi:10.1002/SLCT.201900992

Wang, Y. X. (2011). Superparamagnetic Iron Oxide Based MRI Contrast Agents: Current Status of Clinical Application. Quant. Imaging Med. Surg. 1, 35-40. doi:10.3978/J.ISSN.2223-4292.2011.08.03

WHO (2020). Global Health Estimates 2020: Deaths by Cause, Age, Sex, by Country and by Region, 2000-2019. Geneva: World Health Organization.

Wilczewska, A. Z., Niemirowicz, K., Markiewicz, K. H., and Car, H. (2012). Nanoparticles as Drug Delivery Systems. Pharmacol. Rep. 64, 1020-1037. doi:10.1016/S1734-1140(12)70901-5

Wills, J. W., Summers, H. D., Hondow, N., Sooresh, A., Meissner, K. E., White, P. A., et al. (2017). Characterizing Nanoparticles in Biological Matrices: Tipping Points in Agglomeration State and Cellular Delivery In Vitro. ACS Nano 11, 11986-12000. doi:10.1021/ACSNANO.7B03708

Wu, W., Wu, Z., Yu, T., Jiang, C., and Kim, W.-S. (2015). Recent Progress on Magnetic Iron Oxide Nanoparticles: Synthesis, Surface Functional Strategies and Biomedical Applications. Sci. Technol. Adv. Mater. 16, 023501. doi:10.1088/ 1468-6996/16/2/023501

Xie, G., Wang, C., Sun, J., and Zhong, G. (2011). Tissue Distribution and Excretion of Intravenously Administered Titanium Dioxide Nanoparticles. Toxicol. Lett. 205, 55-61. doi:10.1016/J.TOXLET.2011.04.034

Xie, J., Lee, S., and Chen, X. (2010). Nanoparticle-based Theranostic Agents. Adv. Drug Deliv. Rev. 62, 1064-1079. doi:10.1016/J.ADDR.2010.07.009

Yang, C.-C., Wang, C.-X., Kuan, C.-Y., Chi, C.-Y., Chen, C.-Y., Lin, Y.-Y., et al. (2020). Using C-Doped TiO2 Nanoparticles as a Novel Sonosensitizer for Cancer Treatment. Antioxidants 9, 880. doi:10.3390/ANTIOX9090880

Yang, Q., Jacobs, T. M., McCallen, J. D., Moore, D. T., Huckaby, J. T., Edelstein, J. N., et al. (2016). Analysis of Pre-existing IgG and IgM Antibodies against
Polyethylene Glycol (PEG) in the General Population. Anal. Chem. 88, 11804-11812. doi:10.1021/ACS.ANALCHEM.6B03437

Yang, Q., and Lai, S. K. (2015). Anti-PEG Immunity: Emergence, Characteristics, and Unaddressed Questions. WIREs Nanomed Nanobiotechnol 7, 655-677. doi:10.1002/WNAN.1339

Yang, R.-M., Fu, C., Fang, J., Xu, X., Wei, X., Tang, W., et al. (2017). Hyaluronanmodified Superparamagnetic Iron Oxide Nanoparticles for Bimodal Breast Cancer Imaging and Photothermal Therapy. Int. J. Nanomedicine 12, 197-206. doi:10.2147/IJN.S121249

Yoo, J., Park, C., Yi, G., Lee, D., and Koo, H. (2019). Active Targeting Strategies Using Biological Ligands for Nanoparticle Drug Delivery Systems. Cancers 11, 640. doi:10.3390/CANCERS11050640

Yuan, L., Meng, S., Zhou, Y., and Yue, Z. (2013). Controlled Synthesis of Anatase TiO2 Nanotube and Nanowire Arrays via AAO Template-Based Hydrolysis. J. Mater. Chem. A. 1, 2552-2557. doi:10.1039/C2TA00709F

Yurt, F., Ocakoglu, K., Ince, M., Colak, S. G., Er, O., Soylu, H. M., et al. (2018). Photodynamic Therapy and Nuclear Imaging Activities of Zinc Phthalocyanine-Integrated $\mathrm{TiO} 2$ Nanoparticles in Breast and Cervical Tumors. Chem. Biol. Drug Des. 91, 789-796. doi:10.1111/CBDD.13144

Zelepukin, I. V., Yaremenko, A. V., Shipunova, V. O., Babenyshev, A. V., Balalaeva, I. V., Nikitin, P. I., et al. (2019). Nanoparticle-based Drug Delivery via RBCHitchhiking for the Inhibition of Lung Metastases Growth. Nanoscale 11, 1636-1646. doi:10.1039/C8NR07730D

Zeng, L., Pan, Y., Tian, Y., Wang, X., Ren, W., Wang, S., et al. (2015). Doxorubicinloaded NaYF4:Yb/Tm-TiO2 Inorganic Photosensitizers for NIR-Triggered Photodynamic Therapy and Enhanced Chemotherapy in Drug-Resistant Breast Cancers. Biomaterials 57, 93-106. doi:10.1016/ J.BIOMATERIALS.2015.04.006

Zhang, G., Liao, Y., and Baker, I. (2010). Surface Engineering of Core/shell Iron/ iron Oxide Nanoparticles from Microemulsions for Hyperthermia. Mater. Sci. Eng. C 30, 92-97. doi:10.1016/J.MSEC.2009.09.003

Zhao, J., Yao, L., Nie, S., and Xu, Y. (2021). Low-viscosity Sodium Alginate Combined with $\mathrm{TiO} 2$ Nanoparticles for Improving Neuroblastoma Treatment. Int. J. Biol. Macromolecules 167, 921-933. doi:10.1016/ J.IJBIOMAC.2020.11.048

Zhu, Y.-J., and Chen, F. (2014). Microwave-assisted Preparation of Inorganic Nanostructures in Liquid Phase. Chem. Rev. 114, 6462-6555. doi:10.1021/ CR400366S

Zou, Y., Li, D., Wang, Y., Ouyang, Z., Peng, Y., Tomás, H., et al. (2020). Polyethylenimine Nanogels Incorporated with Ultrasmall Iron Oxide Nanoparticles and Doxorubicin for MR Imaging-Guided Chemotherapy of Tumors. Bioconjug. Chem. 31, 907-915. doi:10.1021/ACS.BIOCONJCHEM.0C00036

Conflict of Interest: The authors declare that the research was conducted in the absence of any commercial or financial relationships that could be construed as a potential conflict of interest.

Publisher's Note: All claims expressed in this article are solely those of the authors and do not necessarily represent those of their affiliated organizations, or those of the publisher, the editors and the reviewers. Any product that may be evaluated in this article, or claim that may be made by its manufacturer, is not guaranteed or endorsed by the publisher.

Copyright (c) 2021 Kawassaki, Romano, Dietrich and Araki. This is an open-access article distributed under the terms of the Creative Commons Attribution License (CC $B Y)$. The use, distribution or reproduction in other forums is permitted, provided the original author(s) and the copyright owner(s) are credited and that the original publication in this journal is cited, in accordance with accepted academic practice. No use, distribution or reproduction is permitted which does not comply with these terms. 